\title{
Seasonal differences in the response of Arctic cyclones to climate change in CESM1
}

\author{
Jonathan J. Day ${ }^{1}$ (I) $\cdot$ Marika M. Holland ${ }^{2} \cdot$ Kevin I. Hodges ${ }^{3}$
}

Received: 23 January 2017 / Accepted: 11 June 2017 / Published online: 16 June 2017

(c) The Author(s) 2018. This article is an open access publication

\begin{abstract}
The dramatic warming of the Arctic over the last three decades has reduced both the thickness and extent of sea ice, opening opportunities for business in diverse sectors and increasing human exposure to meteorological hazards in the Arctic. It has been suggested that these changes in environmental conditions have led to an increase in extreme cyclones in the region, therefore increasing this hazard. In this study, we investigate the response of Arctic synoptic scale cyclones to climate change in a large initial value ensemble of future climate projections with the CESM1-CAM5 climate model (CESM-LE). We find that the response of Arctic cyclones in these simulations varies with season, with significant reductions in cyclone dynamic intensity across the Arctic basin in winter, but with contrasting increases in summer intensity within the region known as the Arctic Ocean cyclone maximum. There is also a significant reduction in winter cyclogenesis events within the Greenland-Iceland-Norwegian sea region. We conclude that these differences in the response of cyclone intensity and cyclogenesis, with season, appear to be closely linked to changes in surface temperature gradients in the high latitudes, with Arctic poleward temperature gradients increasing in summer, but decreasing in winter.
\end{abstract}

Keywords Arctic cyclones $\cdot$ Extreme weather $\cdot$ Polar climate $\cdot$ Climate change $\cdot$ Storm risk

\section{Introduction}

Unprecedented warming in the Arctic has led to a dramatic reduction in both the extent and thickness of Arctic sea ice (Stroeve et al. 2011), opening up opportunities for business in diverse sectors such as fossil fuel and mineral extraction, shipping and tourism (Jung et al. 2016). Industrial activities in the Arctic are expected to be subject to high levels of investment over the coming decades (Emmerson and Lahn 2012). As a result, there has been an increase in the exposure

Electronic supplementary material The online version of this article (https://doi.org/10.1007/s00382-017-3767-x) contains supplementary material, which is available to authorized users.

Jonathan J. Day

j.j.day@ reading.ac.uk

1 National Centre for Atmospheric Science, Department of Meteorology, University of Reading, Reading, UK

2 National Center for Atmospheric Research, Boulder, USA

3 Department of Meteorology, University of Reading, Reading, UK of humans and infrastructure to environmental risks in the Arctic.

Unlike the mid-latitude storm tracks of the North Atlantic and Pacific, which are most active during winter, in an area of the central Arctic, known as the Arctic Ocean cyclone maximum (AOCM) synoptic scale cyclones are most numerous during summer (Serreze 1995; Serreze and Barrett 2008) (see Figs. 1, 2). However, Arctic cyclones are most dynamically intense during winter (Zhang et al. 2004). The source region of Arctic cyclones also differs depending on the season, with summer cyclones largely originating over the Eurasian continent (Reed and Kunkel 1960; Crawford and Serreze 2016) and winter cyclones largely originate from the North Atlantic and North Pacific (Sorteberg and Walsh 2008; Simmonds et al. 2008) (Figure S1, S2 \& S3). The dramatic warming of the Arctic over the last three decades has reduced both the thickness and area covered by summer sea ice, leaving Arctic waters navigable by shipping exactly during this period of seasonally enhanced cyclone activity in the AOCM region. Therefore, understanding changes in storminess in the region is an important factor required to manage the risks associated with these storms. 


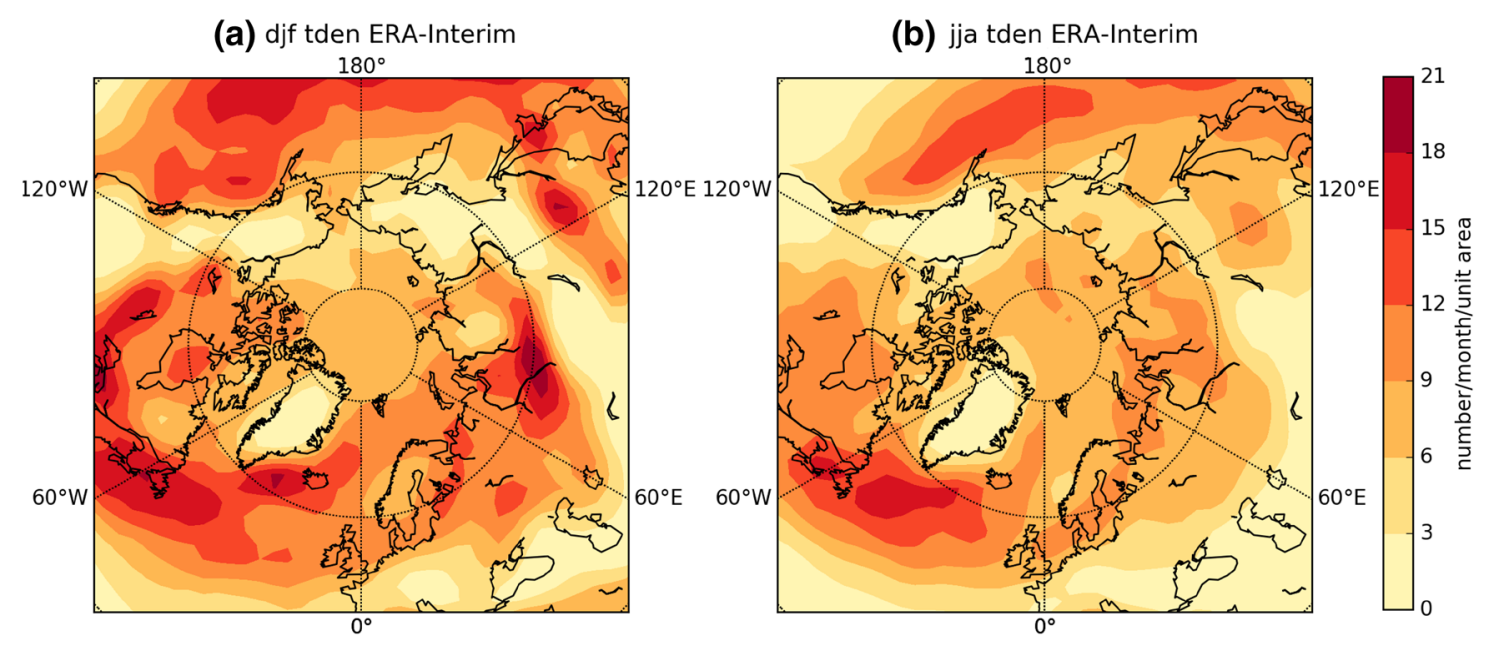

(c) djf tden 20TRcesmLE-ERA-Interim

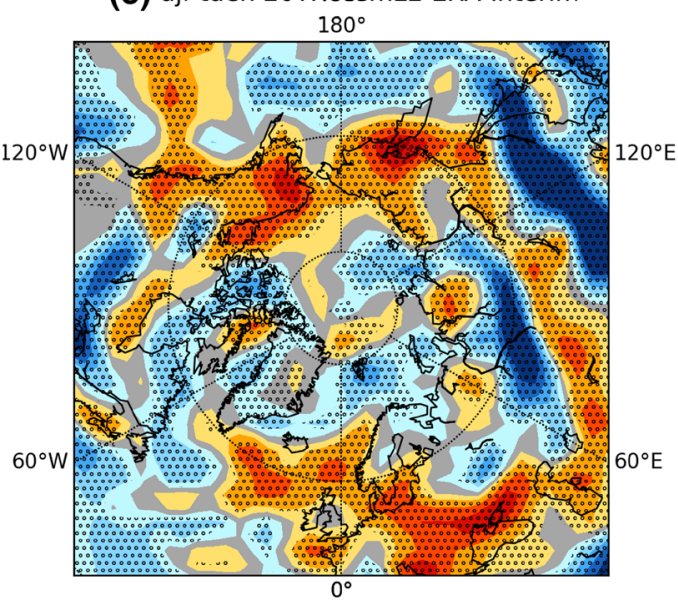

Fig. 1 Track density in ERA-Interim (1990-2005) (top row) and ensemble mean track density bias of historical simulations relative to ERA-Interim, for (left) DJF and (right) JJA. Units are in number of (d) jja tden 20TRcesmLE-ERA-Interim

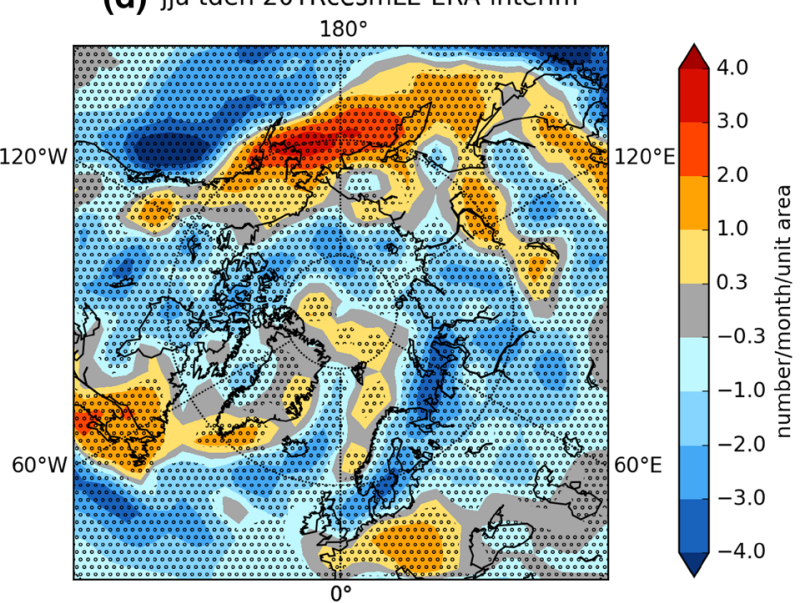

cyclones per month per unit area, where unit area is equivalent to a $5^{\circ}$ spherical cap. In c, d, stippling shows where more than $80 \%$ of ensemble members have a bias of the same sign

Investigations into Arctic cyclone trends using the National Center for Environmental Prediction (NCEP) atmospheric reanalyses (Kistler et al. 2001) have found a significant positive trend in the number of cyclones entering the Arctic from lower latitudes in spring and summer months, but little change in winter (Zhang et al. 2004; Sorteberg and Walsh 2008), however these studies also indicate significant inter-annual and longer timescale variability in these trends. Sepp and Jaagus (2011) confirmed that the number of cyclones entering the Arctic had increased, but found that the total number of cyclones inside the Arctic had not changed significantly, suggesting a reduction in local cyclogenesis. However, analysis of trends appears to be sensitive to the choice of reanalysis used. For example, Simmonds et al. (2008) found a statistically significant trend in the total number of summer cyclones in the Arctic in the NCEP reanalysis for the period (1948-2002) but not in ERA-40 (Uppala et al. 2005). To measure trends in maximum cyclone intensity, these studies have largely focussed on minimum mean sea level pressure (MSLP), and studies generally agree that there is a general reduction in this quantity. A recent intercomparison of cyclone tracking methods by Simmonds and Rudeva (2014) concluded that different methods generally agree on which Arctic cyclones are most intense over the ERA-Interim reanalysis period (1979-2009). However, Chang (2014) cautions that differences in the definitions used in cyclone identification algorithms can lead to differing conclusions when investigating the response of strong cyclones to climate change.

The apparent temporal changes in cyclone statistics have occurred against a backdrop of changes in the mean climate. The warming in the Arctic is amplified with respect to the global mean, particularly outside of the summer months when solar energy absorbed during summer is released back to the atmosphere (Rigor et al. 2000). This pattern is expected to continue into the future 
Fig. 2 Arctic seasonal mean cyclone frequency for ERAInterim (dots) and box plots showing quartiles of mean cyclone frequency for historical simulations (1990-2005) (left) and RCP8.5 simulations (20712080) (right) (\#/month). The bottom panel is as top except for the mean maximum wind speed achieved by cyclones within the Arctic
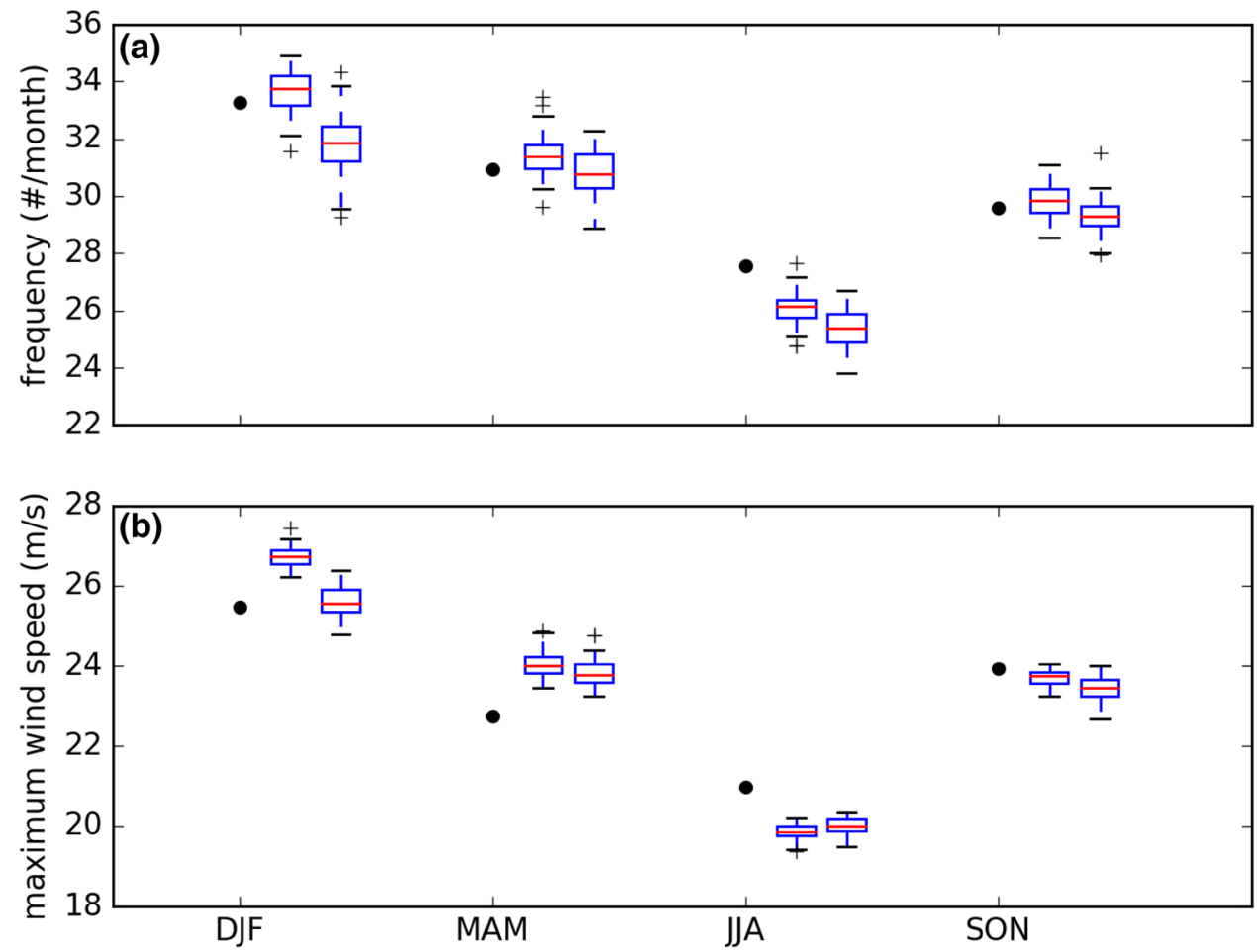

(Manabe and Stouffer 1980; Holland and Bitz 2003). The impact of these changes on both the time-mean and transient large scale atmospheric circulation is an active area of research (e.g. Shepherd 2016) and significant disagreements remain over the role of Arctic warming in modifying planetary scale features, such as the northern hemisphere jet stream (e.g. Francis and Vavrus 2012; Barnes and Screen 2015). However, significantly fewer publications exist on the impact of these changes on synoptic scale weather phenomena.

Understanding the relationship between cyclone activity and the Arctic background climate can also be derived from analysis of year-to-year variability in climate reanalyses. Simmonds and Keay (2009), who performed a correlation analysis and found that years of low September sea ice extent were associated with deeper and larger cyclones, largely due to increased latent heat flux from the ocean due to the absence of sea ice. Subsequent studies have shown that this coupling goes in both directions, and that year-to-year variations in cyclone activity also drive changes in sea ice. Years of anomalously (high) low May-August cyclone activity over the Arctic Ocean tending to be associated with anomalously (high) low September sea ice minima (Screen et al. 2011; Knudsen et al. 2015). A recent example of this was the August 2012 'Great Arctic Cyclone' which is thought to have influenced the record low September sea ice extent seen that year (Zhang et al. 2013).

Another approach is the use of coupled climate model simulations, which have been used to understand and project the response of Arctic cyclones to climate change. Using a vorticity feature tracking algorithm, Orsolini and Sorteberg (2009) found that Arctic summer (JJA) cyclone frequency and dynamic intensity, measured by relative vorticity, significantly increased in the Bergen climate model under two emissions scenarios. This occurs against a backdrop of reduced northern hemisphere storminess. They hypothesised that this increase is associated with an increase in zonal winds and meridional temperature gradient at high latitudes in their simulation, due to the Arctic Ocean warming slowly compared to the surrounding land mass.

Extending the analysis of Arctic storminess in climate model projections to both the Coupled Model Intercomparison Project (CMIP) phase 3 and phase 5 ensembles; Nishii et al. (2014) found a similar increase in Arctic summer storminess across these ensembles. Although their analysis used Eulerian (gridpoint) variance measures, rather than Lagrangian (storm tracking) approach, they come to a similar conclusion to Orsolini and Sorteberg (2009). Further, they found that the magnitude of the response in storminess for a given model was strongly correlated with the magnitude of change in the zonal mean wind and the near surface temperature gradient along the Eurasian coastline across the CMIP models.

The literature on the response of Arctic winter cyclones to climate change from modelling studies shows less agreement and has been less studied. Vavrus (2013) studied changes in extreme cyclones, which occur in autumn and winter, in historical GCM simulations from CMIP5. Using 
a MSLP threshold based counting method, to count changes in extreme cyclone frequency of occurrence, they concluded that extreme cyclones were becoming more frequent, particularly in the high latitude North Atlantic. In contrast Akperov et al. (2014) simulate a reduction in mean Arctic cyclone intensity, in a regional climate model, but do not find significant change in extreme cyclones at high latitudes. Harvey et al. (2014) also find reductions in Arctic winter storminess, using a Eulerian MSLP variance metric, to quantify the future response of storms in the CMIP5 ensemble.

In this study we use a large initial value ensemble produced with the community earth system model version 1 (CESM1-CAM5; Kay et al. 2015) to quantify the response of Arctic synoptic scale cyclones to climate change, to determine if the sign of the response depends on the season and to determine how these changes in transient eddies are related to changes in the background circulation.

This approach of using a large initial-value ensemble has two advantages over previous modelling studies in this area: firstly, the large number of ensemble members enables the forced response to climate change to be well characterised in the model. Secondly, it enables the role of internal variability, which is thought to significantly affect trends in Arctic cyclones (Zhang et al. 2004), and those at lower latitudes (Villarini and Vecchi 2012), to be quantified. In this study, we will focus on DJF and JJA because these seasons experience the largest contrast in terms of the seasonal response to climate change.

\section{Data and methods}

\subsection{CESM1 and the large ensemble}

The CESM1 large ensemble (CESM-LE; Kay et al. 2015) is an ensemble of 40 ensemble members designed to investigate the role of internal variability as a source of uncertainty in projection of climate change. Internal variability is known to be a significant source of uncertainty in projections of Arctic climate change (Day et al. 2012; Hodson et al. 2012; Swart et al. 2015; Jahn et al. 2016). All simulations were conducted with the community earth system model, version 1 , with the community atmosphere model, version 5 (CESM1-CAM5; Hurrell et al. 2013). It consists of coupled atmosphere, ocean, land, and sea ice components all at approximately $1^{\circ}$ horizontal resolution. Treatment of the atmospheric dynamics in this model is similar to the previous version of the model, CAM4, described in Neale et al. (2013).

CAM5 is developed around a finite volume dynamical core, CAM-FV, based on the formulation of Lin (2004). One important aspect for the current study, due to its focus on high latitudes, is the nature of numerical filtering used, to ensure numerical stability, and how this deals with convergent meridians at high latitudes. In order to allow a longer time-step a polar filter is used to stabilise short-wavelength gravity waves, at high latitudes (Neale et al. 2010). This filter closely follows that of Suarez and Takacs (1995), using a fast fourier transform. CAM-FV also includes a fourth order divergence damping term in the momentum calculation, where the damping coefficient is propositional to the cosine of latitude, and therefore reduces to zero at the poles. This arrangement is described in detail by Lauritzen et al. (2012).

In order to generate the large ensemble, initial values from a random year of the 1850 pre-industrial control simulation were used to initialise the first ensemble member. This member was run from 1850 till 2005 following the CMIP5 historical forcing protocol and then from 2005 till 2080 under the Representative Concentration Pathway 8.5 (RCP8.5; see Taylor et al. 2012).

The full state vector of the first ensemble member on Jan 1,1920 was used to initialize every other ensemble member. The initial values used to initialise each simulation differ only by a small random perturbation (order of $10^{-14} \mathrm{~K}$ ) to the initial air temperature field. All other variables were initialised to identical values and the simulations were run from 1920 to 2080 using the forcing already described. Due to the chaotic nature of the climate system, these perturbations grow until initial condition memory is lost creating spread among the ensemble members. Although the exact method of perturbing the initial conditions can affect the spread early in the simulation (Hawkins et al. 2016), a few decades into the simulation the climate state space will be well sampled by the ensemble, since the limit of initial-value predictability for surface ocean and atmospheric variables is about a decade (e.g. Collins et al. 2006; Branstator and Teng 2010). A full description of the CESM-LE can be found in Kay et al. (2015).

The data from the simulations used in the study are the 6-hourly zonal and meridional winds and MSLP, required for the objective cyclone tracking, though these were not output for the entire run due to limitations of long-term storage. Instead, they were output in discrete time windows: 1990-2005 from the historical simulations and 2026-2035 and 2071-2080 during the RCP8.5 projections. As a result, we focus our analysis on these periods which are shorter than the 30-year windows, typically used to define the cyclone climatology in CMIP5 studies (e.g. Zappa et al. 2013a). This means that the contribution of internal variability to the total uncertainty in the projected climate simulated by an individual ensemble member, will be larger than under the CMIP5 protocol, where more years are used to characterise the climate in each period. Nevertheless, because we have so many ensemble members, and thus individual samples with the same model we can accurately characterise the forced response. 


\subsection{Cyclone tracking}

In this study we employ the Hodges (1994, 1996, 1999) objective feature-tracking algorithm to identify and track cyclones. This algorithm has already been used extensively to study extratropical cyclones in both climate models and atmospheric reanalyses (e.g. Hoskins and Hodges 2002; Bengtsson et al. 2006; Zappa et al. 2013a).

The main aspects of this procedure are as follows: firstly, $850 \mathrm{hPa}$ vorticity is computed from the 6-hourly zonal and meridional wind speeds. It is then spectrally filtered to a T42 resolution to reduce the small scale noise and focus on synoptic scale cyclones. The large scale background is also removed for total wavenumbers smaller than six. The spectral coefficients are also tapered to suppress Gibbs oscillations using the method of Sardeshmukh and Hoskins (1984). To identify cyclones the filtered data is first transformed to a uniform grid on a polar stereographic projection of similar resolution to the filtered data in order to prevent the kinds of bias in the identification often seen if using a cylindrical projection, caused by the converging meridians (Sinclair 1997). Cyclones are then identified as maxima in the filtered and projected vorticity that exceed a vorticity of $10^{-5} \mathrm{~s}^{-1}$. The locations are then refined using a B-spline interpolation and steepest ascent method to compute the off-grid locations which helps to produce smoother tracks (Hodges 1994). Once the vorticity maxima are identified they are transformed back to the spherical coordinate system for the tracking. Tracks are first initialised using a nearest neighbor method and then refined by minimizing a cost function for the track smoothness, measured as changes in direction and speed, subject to adaptive constraints on track smoothness and displacement distance (Hodges 1999). The tracking is performed in the spherical coordinate system to prevent the types of biases often associated with tracking on a projection. The tracking methodology is exactly the same as that used in Hoskins and Hodges (2002), Bengtsson et al. (2006) and Zappa et al. (2013a).

To avoid the inclusion of stationary and short-lived features, tracks are filtered so that only the cyclone tracks that have a lifetime greater than 2 days and a length of $1000 \mathrm{~km}$ or more are retained for the final analysis. The sensitivity of this choice was tested by repeating the analysis but filtering tracks with lifetimes greater than 1 day and track length greater than $500 \mathrm{~km}$ and it does not significantly affect the results. These are the values which have typically been used for mid-latitude cyclones (e.g. Hodges et al. 2011) and published case studies of Arctic synoptic scale cyclones indicate that these lifetime and propagation thresholds are suitable choices as Arctic cyclones are typically longer lived than extra-tropical cyclones (Tanaka et al. 2012; Aizawa and Tanaka 2016).
The dynamical intensity of cyclones is measured by referencing the tracks to the full-resolution maximum $850 \mathrm{hPa}$ wind speed by searching for the maximum value within a $6^{\circ}$ spherical cap centered on the tracked vorticity maxima. The closest MSLP minima within a $5^{\circ}$ spherical cap region are also added to the tracks using a B-spline fit to the MSLP fields and a steepest descent minimization starting from the vorticity center. Spatial maps of track density and of the mean wind speeds associated with cyclones are then computed using the spherical kernel method described by Hodges (1996).

\section{Future response in mean storminess}

\subsection{Model biases}

Before investigating the response of Arctic cyclones in CESM1 to climate change it is informative to investigate and describe the ability of CESM1 to recreate observed track density and dynamic intensity. To do this storm track statistics in the historical simulations (1990-2005) are compared with the ERA-Interim reanalysis (Dee et al. 2011) for the same period. However, it should be noted that reanalyses can differ with respect to the exact intensity and frequency of Arctic cyclones (Tilinina et al. 2014).

The model performs well in capturing the basic characteristics of the observed seasonal cycle of Arctic cyclone number and maximum wind speed within the Arctic region (north of $67.5^{\circ}$ ) as shown in Fig. 2 and Table 1 respectively, with cyclones being dynamically more intense and more numerous in winter than in summer in both the CESM1 and ERA-Interim. Biases in cyclone frequency are of magnitude less than $6 \%$ in all seasons. However, the area averaged picture masks significant regional biases.

In winter the North Atlantic storm track is too zonal in CESM1, extending too far south into central Europe, with too few cyclones making their way into the GIN and Barents Sea region (see Fig. 1). This is a bias common to many climate models (Zappa et al. 2013b). Too few cyclogenesis events occur over northern Eurasia in CESM1, leading to a negative bias in track density in this region and over the eastern Arctic Ocean (see Figures S1, S2).

Biases in the summer track density in CESM1 are more consistent in sign than those in winter, with significant negative biases in track density across most of the Arctic and North Atlantic. These biases are partly caused by a lack of cyclogenesis over northern Eurasia and also a lack of cyclones entering the Arctic from the North Atlantic (Figure $\mathrm{S} 1 \& \mathrm{~S} 2$ ). Biases in track density are largest over the coastal region north of Scandinavia and along the Northwest Russian coastline. This results in a fairly weak Arctic Ocean cyclone maximum (Figure S3). This general low track 
Table 1 ERA-Interim cyclone frequency and maximum wind speed in the Arctic and Arctic Ocean cyclone maximum (AOCM) regions (mean over the period 1990-2005) and percentage bias in the both quantities in the CESM1 historical simulation ensemble mean. The percentage of ensemble members that agree on the bias is stated as a measure of significance. Biases are highlighted in bold when more than $80 \%$ of ensemble members agree on the sign of the bias

\begin{tabular}{|c|c|c|c|c|}
\hline & DJF & MAM & JJA & SON \\
\hline \multicolumn{5}{|l|}{ Arctic } \\
\hline ERA-I \# per month & 33.3 & 30.9 & 27.6 & 29.6 \\
\hline CESM HIST count bias (\%) and $\%$ agreement & $1.1(70)$ & $1.5(75.0)$ & $\mathbf{- 5 . 4}(97.5)$ & $0.7(70)$ \\
\hline ERA-I maximum wind speed $(\mathrm{m} / \mathrm{s})$ & 25.5 & 22.8 & 21.0 & 23.9 \\
\hline CESM HIST max wind bias (\%) and \% agreement & $\mathbf{5 . 0}(100)$ & $\mathbf{5 . 6}(100)$ & $-\mathbf{5 . 3}(100)$ & $-\mathbf{0 . 9}(85.0)$ \\
\hline \multicolumn{5}{|l|}{$\mathrm{AOCM}$} \\
\hline ERA-I \# per month & 11.2 & 11.4 & 11.4 & 11.0 \\
\hline CESM HIST count bias (\%) and agreement (\%) & $10.9(100)$ & $3.3(67.5)$ & $-6.0(95)$ & $-2.0(62.5)$ \\
\hline ERA-I maximum wind speed $(\mathrm{m} / \mathrm{s})$ & 22.0 & 19.9 & 19.8 & 20.9 \\
\hline CESM HIST max wind bias (\%) and agreement (\%) & $8.0(100)$ & $4.0(100)$ & $-\mathbf{5 . 2}(100)$ & $-2.0 \%(62.5)$ \\
\hline
\end{tabular}

density bias across the northern hemisphere is a common property of CMIP5 models, and may be related low levels of baroclinicity and weak polar front jet over Eurasia in models (Lee 2014).

The large ensemble mean shows biases in maximum wind speed, consistent across most ensemble members, in all seasons. However, regionally they are within $6 \%$ of the ERA-Interim values with DJF and MAM cyclones being too strong in the model but JJA and SON cyclones being too weak (Table 1).

\subsection{Mean cyclone response}

In this section the change in the cyclone statistics between the historical and RCP8.5 periods will be expressed as a percentage. This is because biases in the model mean that the absolute values are somewhat arbitrary.

Between the two periods there is a general reduction in track density (Fig. 2) and in the frequency of cyclones (Table 2) in the Arctic region (north of $67.5^{\circ} \mathrm{N}$ ) in all seasons, however the only statistically significant change occurs in DJF, where the frequency decreases by more than $5 \%$.
There is some intra-ensemble variability in the magnitude of the change purely because each ensemble member has a slightly different evolution due to internal variability, however in DJF $90 \%$ of ensemble members agree on the sign of this change (see Fig. 2).

The winter response in track density is largest and most statistically significant in the Atlantic sector of the Arctic, with more than $80 \%$ of ensemble members agreeing on the sign of the response in this region (see Fig. 3). There is a concurrent increase in track density on the equatorward flank of the North Atlantic storm track, suggesting that these changes in the Arctic are the result of the tilt of the North Atlantic storm track becoming more zonal, which has been seen in future projections with other CMIP5 models (Zappa et al. 2013a). This goes hand-in-hand with a reduction in cyclogenesis to the east of Greenland (Fig. 3e).

A significant reduction in winter cyclone intensity within the Arctic region is simulated by all ensemble members (Table 1) and this reduction extends across the Arctic basin, but is largest in a band extending from the GIN sea to the north pole, where the reduction in mean maximum wind speed is over $1.5 \mathrm{~ms}^{-1}$ (Fig. 3c).
Table 2 Ensemble mean changes of cyclone frequency and maximum wind speed in the Arctic and Arctic Ocean cyclone maximum (AOCM) between the historical simulation (1990-2005) and RCP8.5 simulations (2071-2080). Changes are expressed as a percentage of the historical values. The percentage of ensemble members that agree on the sign of the change is stated as a measure of significance. Changes where more than $80 \%$ of ensemble members agree on the sign are highlighted in bold

\begin{tabular}{|c|c|c|c|c|}
\hline & DJF & MAM & JJA & SON \\
\hline \multicolumn{5}{|l|}{ Arctic } \\
\hline Change in frequency $(\%)$ and $(\%)$ agreement & $\mathbf{- 5 . 4}(90)$ & $-1.6(65.1)$ & $-2.7(77.5)$ & $-1.5(72.5)$ \\
\hline Mean change in maximum mean wind speed and $\%$ agreement & $-4.2(100)$ & $-0.8(70.0)$ & $0.7(67.5)$ & $\mathbf{- 1 . 1}(82.5)$ \\
\hline \multicolumn{5}{|l|}{$\mathrm{AOCM}$} \\
\hline Change in frequency $(\%)$ and $(\%)$ agreement & $-\mathbf{5 . 9}(80)$ & $0.8(62.5)$ & $-1.3(65.0)$ & $-2.5(67.5)$ \\
\hline Mean change in maximum wind speed and $\%$ agreement & $-4.7(100)$ & $0.5(62.5)$ & $2.3(87.5)$ & $\mathbf{- 2 . 6}(87.5)$ \\
\hline
\end{tabular}



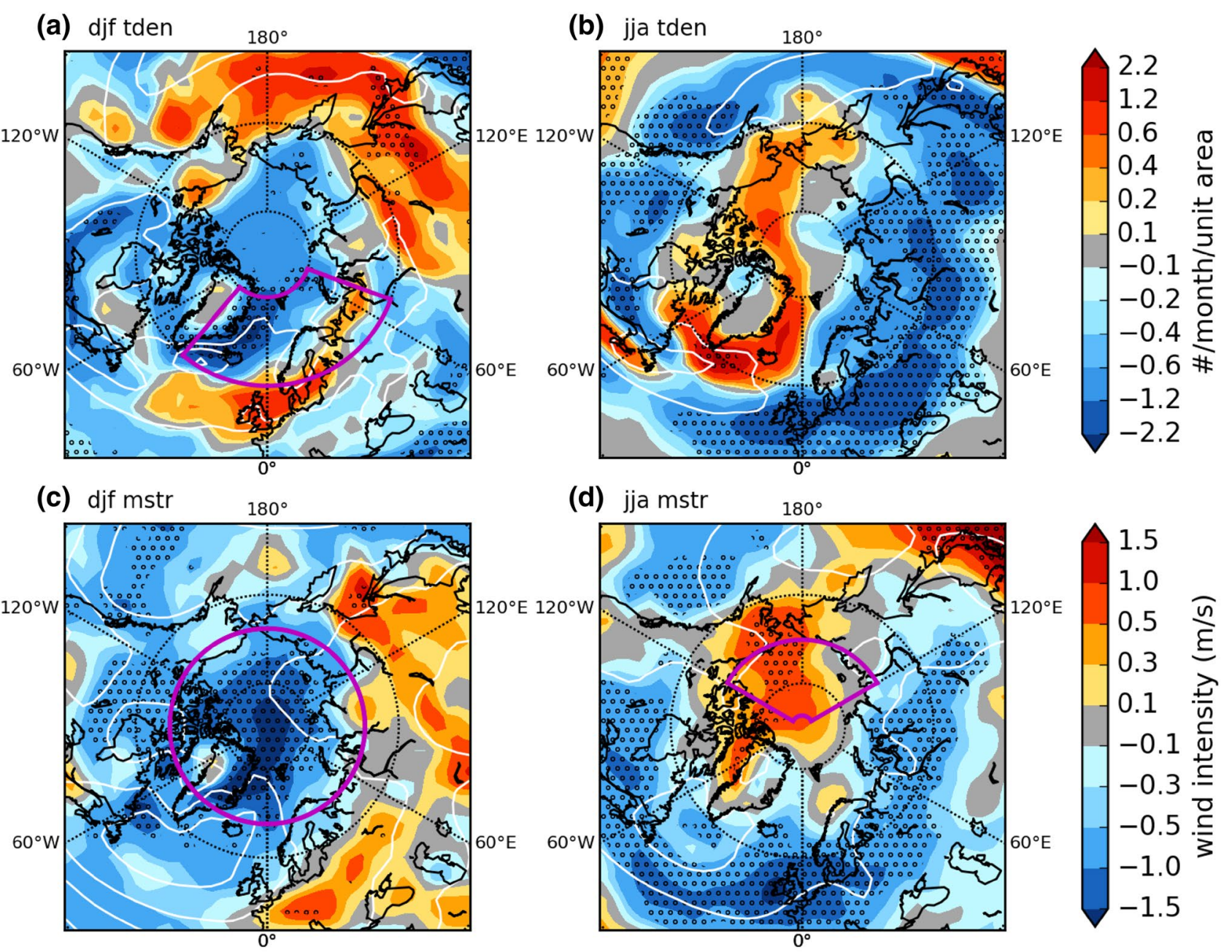

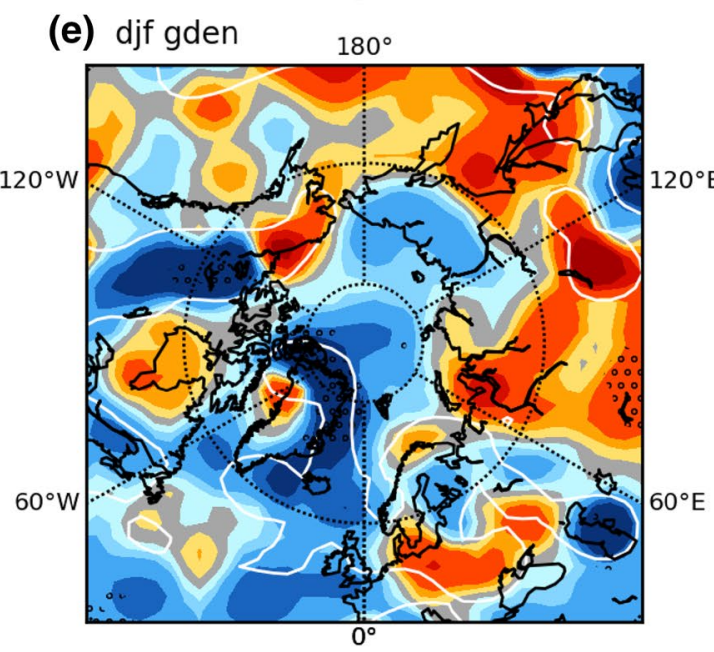

Fig. 3 Ensemble mean response in track density (top row); dynamical intensity, measured by $850 \mathrm{hPa}$ wind speed (middle row); and cyclone genesis density (bottom row). Stippling indicates where more than $80 \%$ of ensemble members agree on the sign of the response. The (f) jja gden $180^{\circ}$

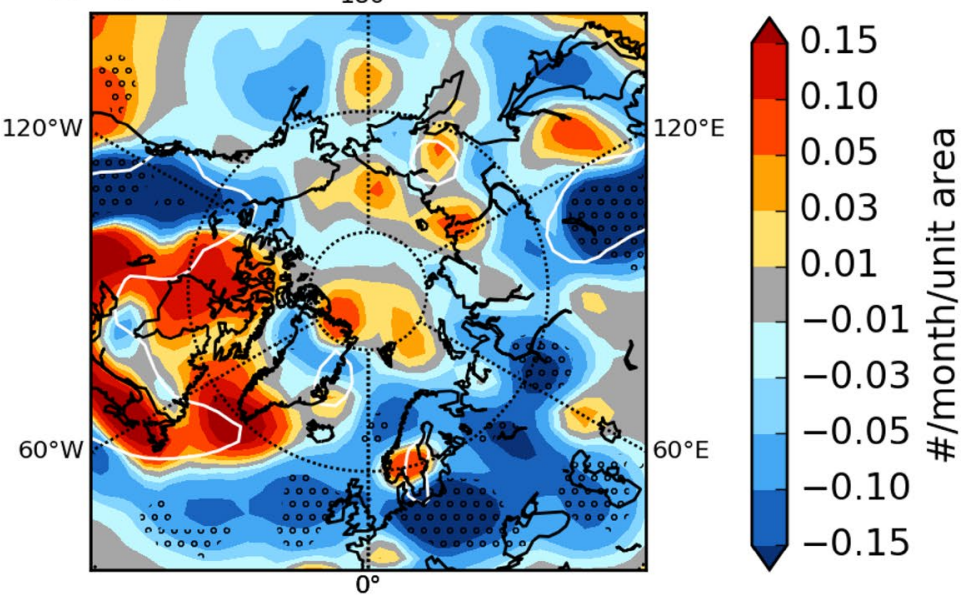

purple box in subfigure a indicates the boundary of the GINB region described in the analysis, the Arctic and AOCM regions are shown in c and $\mathbf{d}$ respectively. White contours show the mean HIST climatology for each field 
(a)

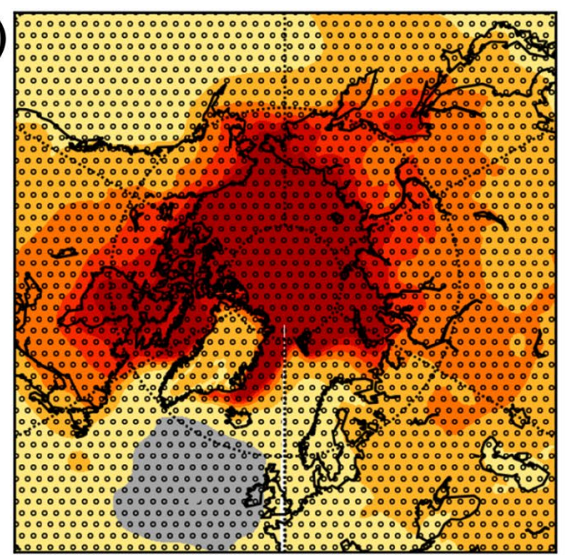

(c)

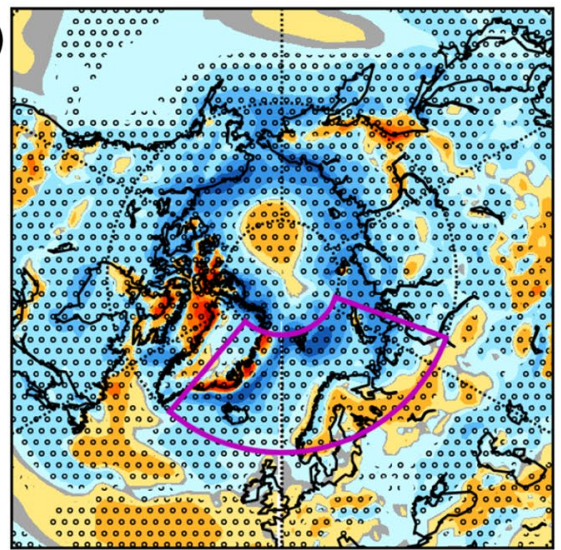

(e)

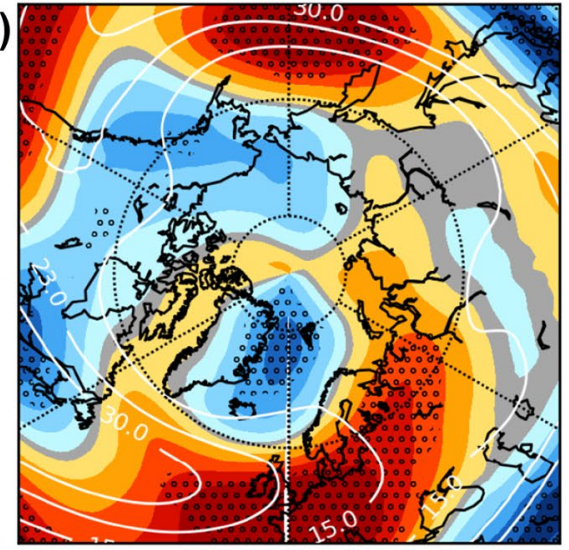

(g)

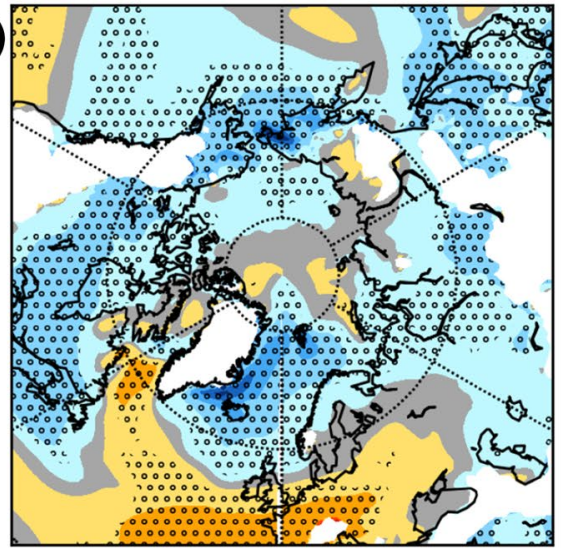

(b)

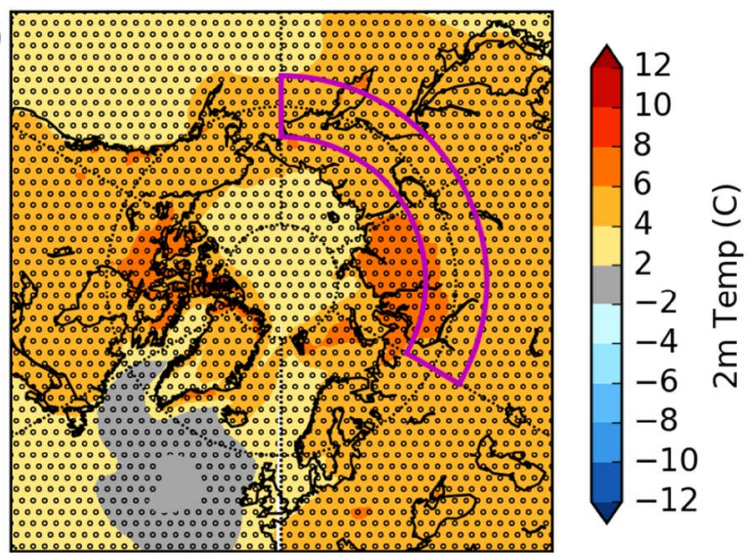

(d)

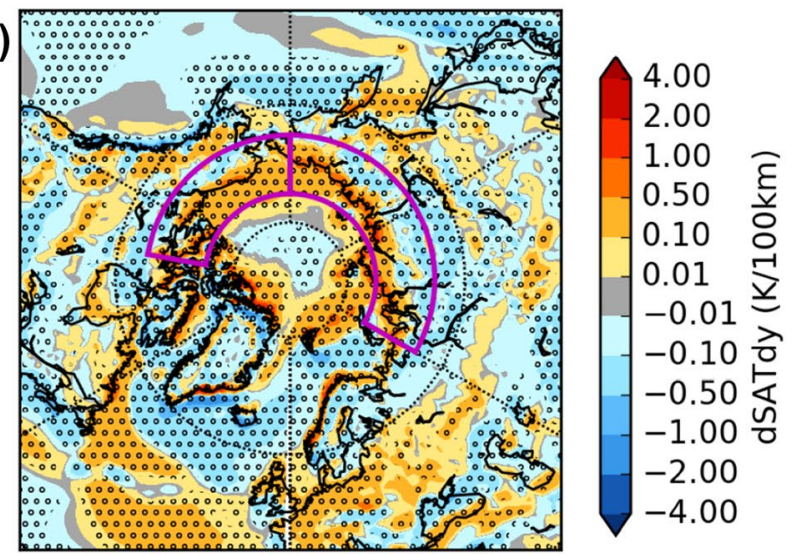

(f)

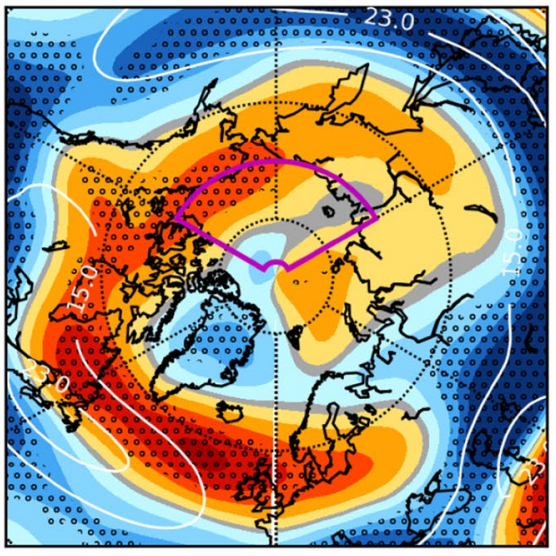

(h)

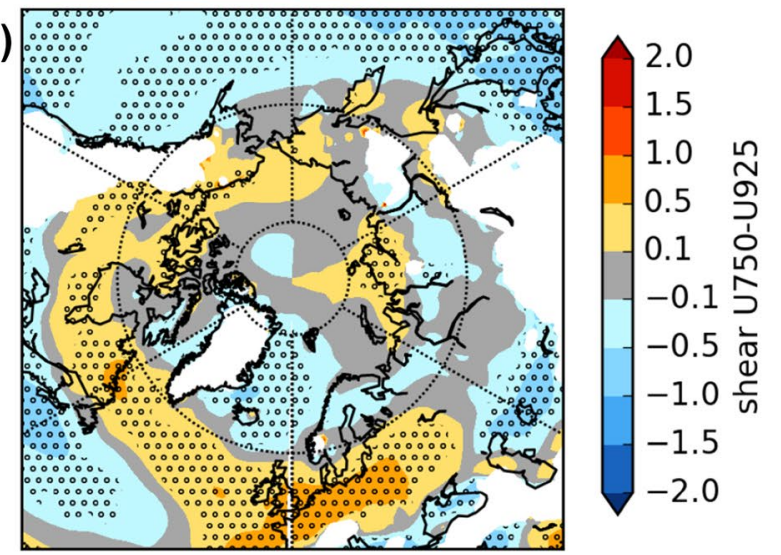


4Fig. 4 Change in background climate (RCP8.5-HIST) for DJF (left column) and JJA (right column) for $2 \mathrm{~m}$ temperature (top row), the equatorward meridional $2 \mathrm{~m}$ temperature gradient (dSAT/dy; second row), $250 \mathrm{hPa}$ zonal wind (third row; the climatological field is shown in white contours) and the zonal component of the vertical wind shear (750-925 hPa; bottom row). The purple box in subfigure c indicates the boundary of the GINB region described in the analysis, the Eurasian Arctic frontal zone (EAFZ) and North American Arctic frontal zone (AAFZ) are shown in $\mathbf{d}$

In summer, only two high latitude regions experience significant changes in track density, the region from northern Scandinavia eastward to the East Siberian Sea experiences a significant reduction in track density and the area south of Greenland experiences a significant increase. Elsewhere in the Arctic, all anomalies in track density are insignificant (see Fig. 3b).

There are also significant changes to cyclone intensity in summer within the Arctic. In contrast to the other seasons, which all experience a decrease in cyclone intensity within the AOCM region $\left(70-87.5^{\circ} \mathrm{N}, 120-240^{\circ} \mathrm{E}\right)$, the ensemble mean increases by $2.3 \%$ (see Table 2; Figure S4) with similar increases over Alaska and the Canadian Archipelago as well. On the other hand, much of Northern Eurasia experiences a significant reduction in intensity (Fig. 3d).

\subsection{Relationship to changes in the background climate}

Amplified surface warming in the Arctic, compared to lower latitudes, can be seen in the simulations (Fig. 4). This effect is a well-known feature of global warming (e.g. Manabe and Stouffer 1980) and a common feature in climate model projections (Holland and Bitz 2003). In summer, increased radiative heat flux at the surface is associated with increased sea ice melt and heating of the upper ocean that is enhanced by the ice-albedo feedback. As such, the surface air temperature shows less increase during these months as compared to other seasons. Outside of the summer months this heat is released back to the atmosphere leading to enhanced warming in winter compared to summer and amplified warming in the lower troposphere (Serreze et al. 2009; Screen and Simmonds 2010). It can be seen that the warming in these CESM-LE simulations is also associated with dramatic sea ice loss (Figure S5).

A feature of the warming that has been less discussed is the fact that in summer the region of strongest warming is not over the Arctic Ocean, but over land. This is caused by two factors, firstly the reduction in snowcover leading to a snow-albedo feedback over land (e.g. Hall and Qu 2006) and secondly due to the fact that the land has a lower heat capacity than the open ocean. This differential warming leads to an increase in the strength of the equatorward meridional $2 \mathrm{~m}$ temperature gradient, dSAT/dy, across the Arctic coastline, which is a region of strong temperature gradients in summer months, and is consequently referred to as the Arctic frontal zone (AFZ, see Fig. 4d). The results of Crawford and Serreze (2016) suggest that stronger temperature gradients in the AFZ enhance the dynamical intensity of cyclones passing through this region, so one might expect the simulated increase in this gradient in the RCP8.5 simulations to lead to an increase in cyclone intensities in the AOCM region (as seen in Fig. 3) compared to the historical period. Surprisingly, analysis of the smoothed vorticity tendency based on the 6-hourly timesteps did not reveal a significant increase in the growth of cyclones in this region in the RCP 8.5 climate, but the maximum wind speed does show an increase (not shown). This suggests that changes in the large-scale background circulation are playing a more important role than the lower tropospheric baroclinic instability.

During summer, changes in the large-scale circulation are also observed. Figure $4 \mathrm{f}$ shows a significant increase in $250 \mathrm{hPa}$ zonal wind, also present in the lower troposphere (not shown). This is particularly prominent in the AOCM and over North Alaska, where the largest increases in Arctic cyclone intensity are simulated. This region also experiences an increase in wind shear in the lower troposphere which is also likely to influence the dynamical intensity. Both Orsolini and Sorteberg (2009) and Nishii et al. (2014), suggest that the increase in zonal wind in climate models is a thermally driven response to the change in temperature gradient.

Large changes in surface temperature gradients are also seen in winter months (see Fig. 4c). There are large reductions in dSAT/dy in the North Atlantic and North Pacific associated with a northward shift of the sea ice edge as well as an amplified warming of the sea ice surface. These regions are collocated with regions of reduced $850 \mathrm{hPa}$ zonal wind and reduced wind shear. These reductions in baroclinic conditions are in regions of cyclone development and dynamical enhancement (e.g. Klein and Heinemann 2002) and lead to a significant reduction in cyclogenesis in the GIN and Barents Sea as well as reduction in the strength of cyclones in the Arctic, downstream of these regions (see Fig. 3c). Although the major source regions for Arctic cyclones in winter are the North Atlantic and north Pacific (Zhang et al. 2004; Sorteberg and Walsh 2008), which experience reduced cyclone activity; local changes in the Arctic also play a role; analysis of relative vorticity tendencies suggest that the growth rates are lower and decay rates are higher within the Arctic basin. Changes in the mean large-scale circulation in the CESM-LE are consistent with those presented by Gervais et al. (2016).

\subsection{Causes of ensemble variance}

The multi-model study into Arctic cyclones by Nishii et al. (2014) explored the relationship between storminess in the AOCM region and changes in background climate, such as 
dSAT/dy and U850 across the CMIP3 and CMIP5 ensembles. If inter-model differences in the response of the background circulation are significantly correlated with intermodel differences in the response of storminess it provides some confidence that the co-existence of anomalies in these properties in the multi-model mean response to external forcing are actually causally related. Here we explore these relationships across the CESM-LE, but with a key difference. In the analysis of Nishii et al. (2014) the intra-ensemble variance is due to both inter-model differences in the forced response to climate change and internal variability, whereas in the CESM-LE differences between ensemble members are only due to internal variability.

Intra-ensemble variations in the response of cyclone statistics in the regions we describe above are indeed significantly correlated with the large-scale climate response. During JJA both the change in the average number of cyclones passing through the AOCM region, in a given ensemble member, and their maximum intensity within the region is significantly correlated with the mean $850 \mathrm{hPa}$ zonal wind (see Fig. 5a, b). Further, variations in JJA U850 are also significantly correlated with changes in the surface temperature gradient within the AOCM (see Fig. 5c), but variability in AOCM cyclone frequency and intensity is not (not shown). In contrast to Nishii et al.'s analysis of CMIP5 inter-model variability, we do not find a significant correlation between the Eurasian Arctic frontal zone (EAFZ; $60-180^{\circ} \mathrm{E}$, $65-75^{\circ} \mathrm{N}$; see Fig. $4 d$ ) and either cyclone intensity (Fig. 4d) or U850 (not shown) in the AOCM region. This is consistent with the findings of the previous section and indicates that although, as shown by Nishii, inter-model spread in the strength of temperature gradients in the AFZ is an important factor in the strength of response of a given model, it may not be as important for the internal variability. Temperature gradients along the North American coastline in the American Arctic frontal zone (AAFZ; $180-260^{\circ} \mathrm{E}, 65-75^{\circ} \mathrm{N}$ ) are significantly correlated with the U850 in the AOCM region, but are still not correlated with either cyclone intensity of frequency there (see Fig. 5e, f) in this model.

It is easier to appreciate these relationships in the form of spatial maps of correlation coefficients. From Fig. 6 it is clear that intra-ensemble variability in both cyclone frequency and intensity within the AOCM is associated with the large scale atmospheric variability, which is Arctic oscillation-like in its
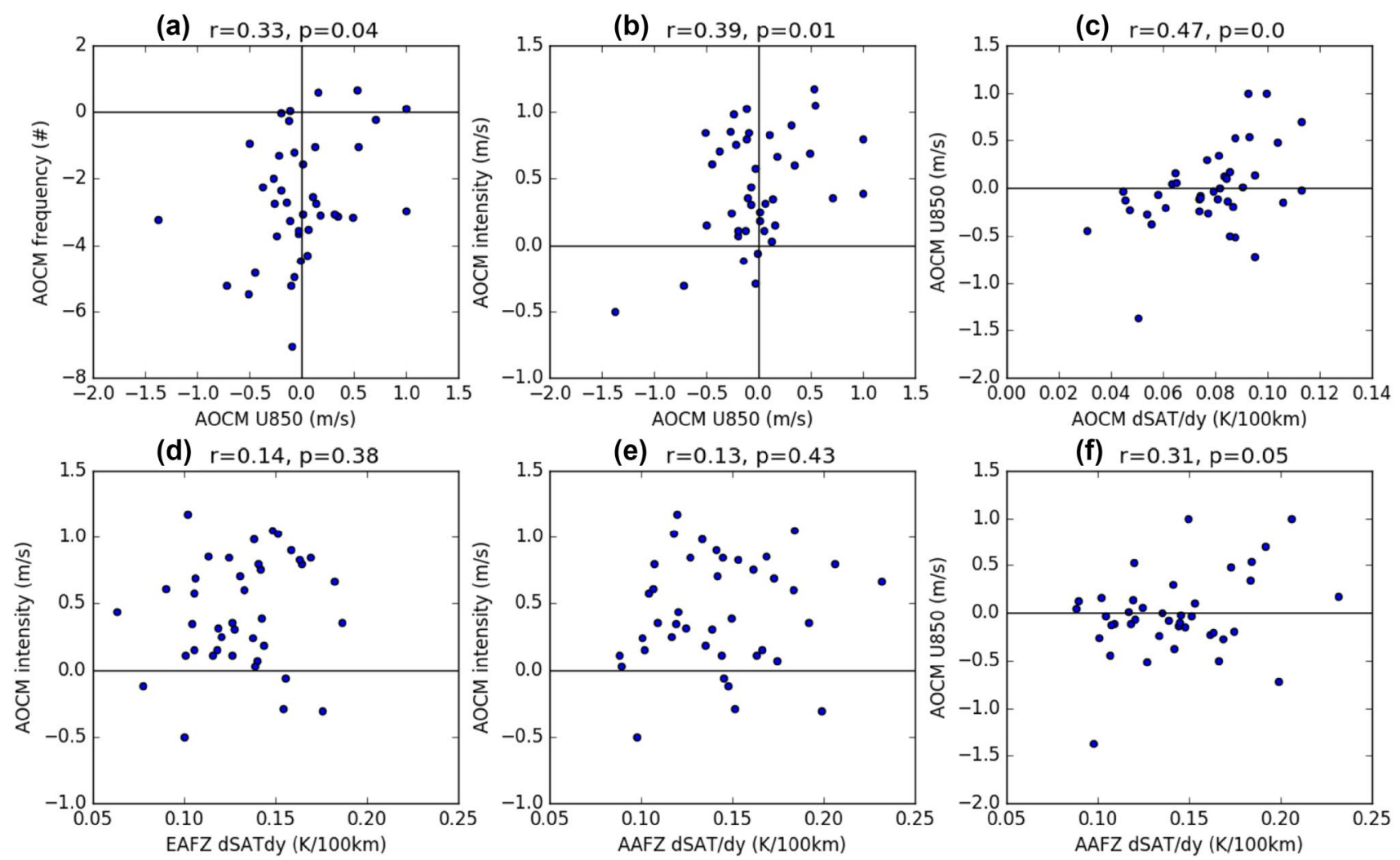

Fig. 5 Scatter plots showing intra-ensemble member correlations between summer (a) mean zonal wind speed and cyclone frequency in the AOCM $\left(70-87.5^{\circ} \mathrm{N}, 120-240^{\circ} \mathrm{E}\right)$, b mean zonal wind speed and cyclone intensity in the AOCM, c mean dSAT/dy against mean meridional temperature gradient in the AOCM, AOCM cyclone intensity and dSAT/dy in the Eurasian Arctic frontal zone (EAFZ) (d), and North American Arctic frontal zone (AAFZ) (e) and between dSAT/dy in the AAFZ and U850 in the AOCM. The correlation coefficient and significance level of each relationship is stated above each subplot 
structure. Ensemble variability in AOCM storminess between the present-day and end of century is negatively correlated with MSLP in the Arctic basin and positively correlated with the associated zonal winds around this region. There does not seem to be a significant correlation with dSAT/dy strength in the Arctic coastal regions.
Fig. 6 Spatial maps of correlation coefficients between the summer change in cyclone frequency (left column) and change in cyclone intensity (right column) within the AOCM, and MSLP (top row), U (second row), $2 \mathrm{~m}$ temp (third row) and dSAT/dy (bottom row) (a) diffnum jja PSL

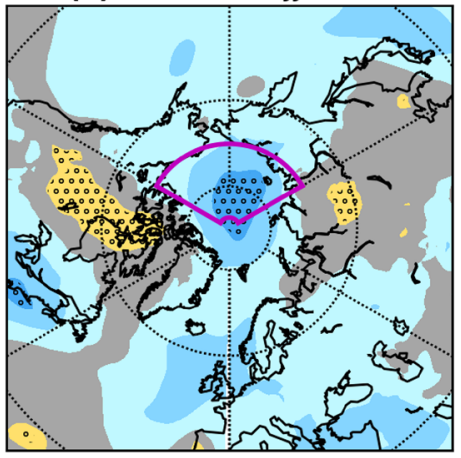

(c) diffnum jja U

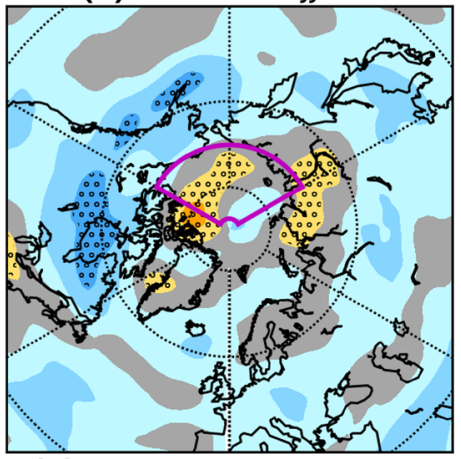

(e) diffnum jja TREFHT

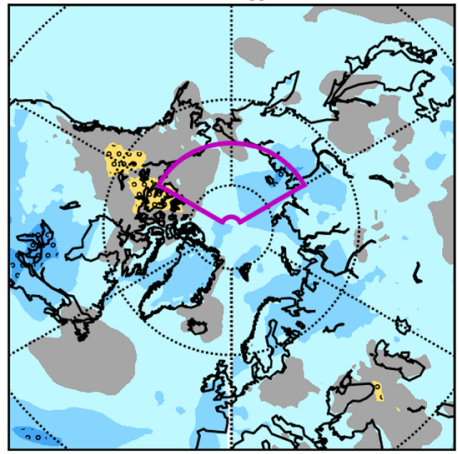

(g) diffnum jja dSATdy

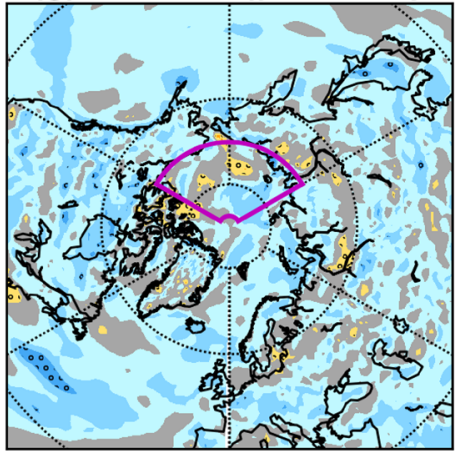

A similar AO-like pattern seems to explain much of the variability in the response of storminess in winter as well (Fig. 7). However, the link with surface temperature is much clearer in winter, with stormier conditions tending to go hand-in-hand with warmer temperatures in the north Pacific. (b) diffwind jja PSL

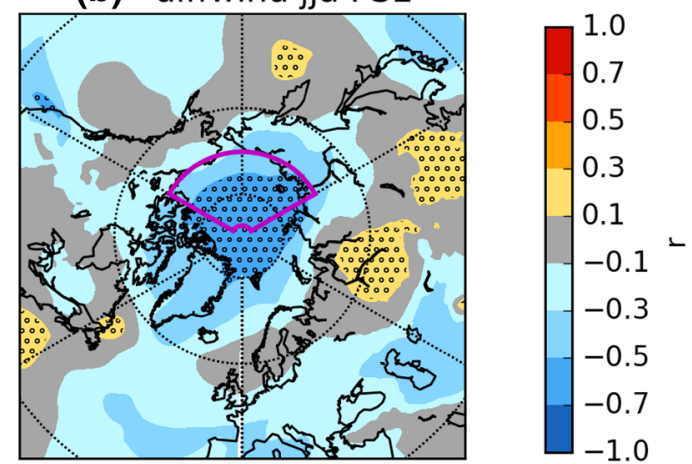

(d) diffwind jja U

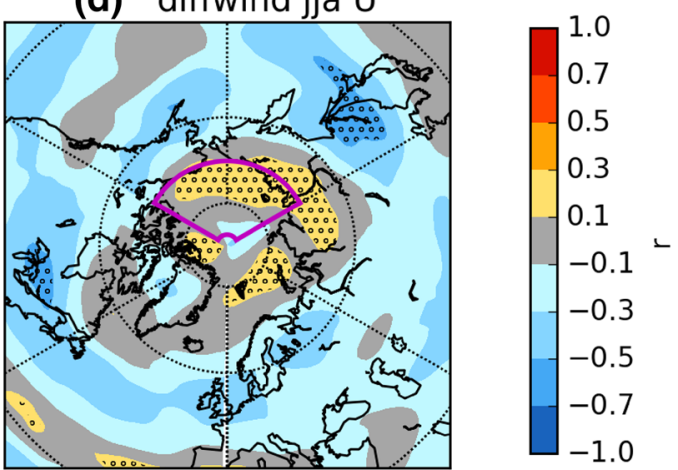

(f) diffwind jja TREFHT

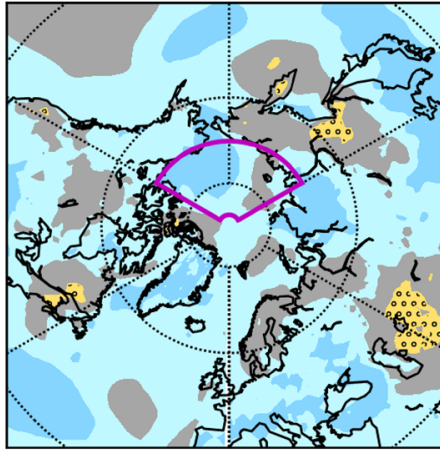

(h) diffwind jja dSATdy

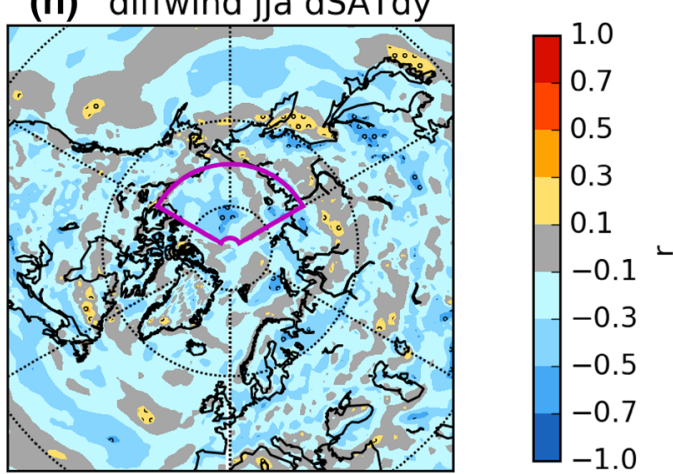




\subsection{The response of intense cyclones}

In order to describe the response of cyclones associated with strong wind speeds, we consider the frequency distribution of dynamical intensity, measured by the maximum $850 \mathrm{hPa}$ wind speed in different high latitude regions. These show the maximum wind speed obtained by storm tracks within each of these regions.

In DJF, there is a clear reduction in the frequency of strong events (greater than the 90th percentile, as calculated
Fig. 7 Spatial maps of correlation coefficients between the winter change in cyclone frequency (left column) and change in cyclone intensity (right column) within the Arctic $\left(>67.5^{\circ} \mathrm{N}\right)$, and MSLP (top row), U (second row), $2 \mathrm{~m}$ temp (third row) and dSAT/dy (bottom row) (a) diffnum djf PSL

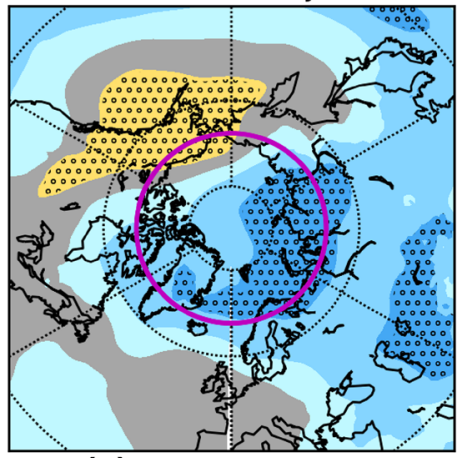

(c) diffnum djf $U$

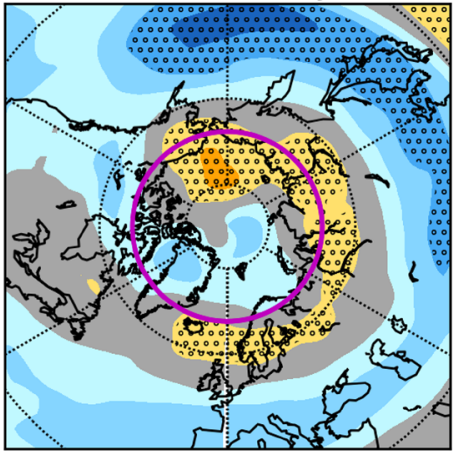

(e) diffnum djf TREFHT

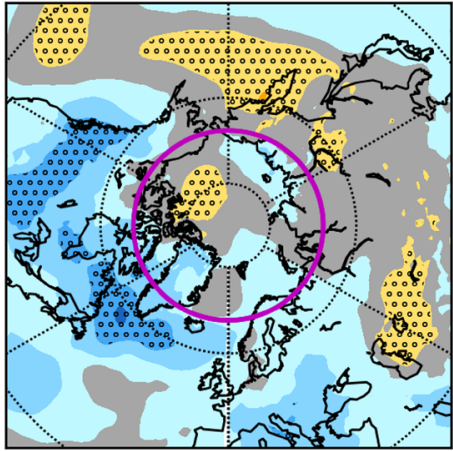

(g) diffnum djf dSATdy

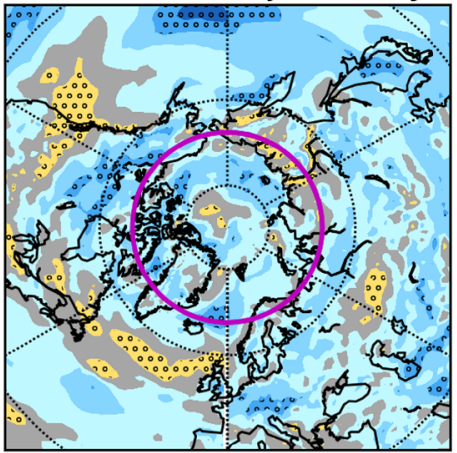

(b) diffwind djf PSL

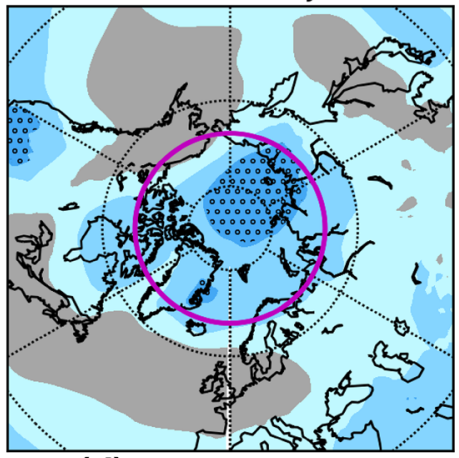

(d) diffwind djf $U$

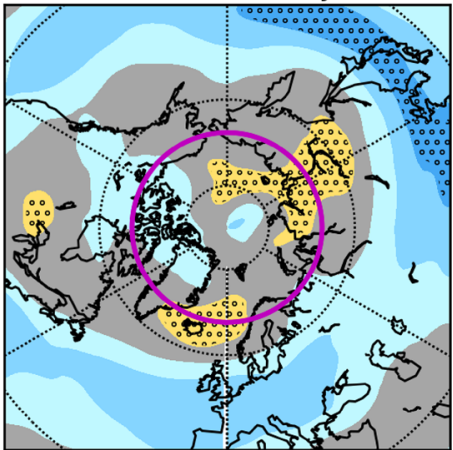

(f) diffwind djf TREFHT

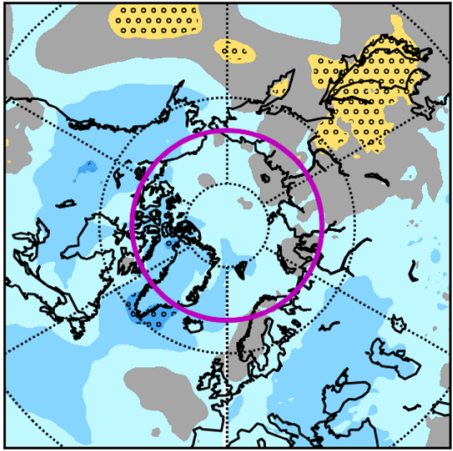

(h) diffwind djf dSATdy

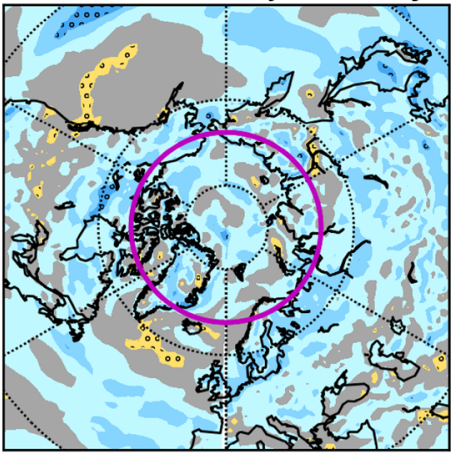

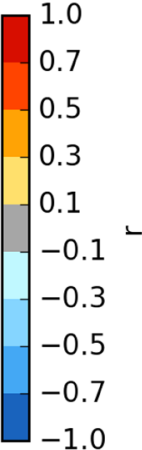

$-1.0$
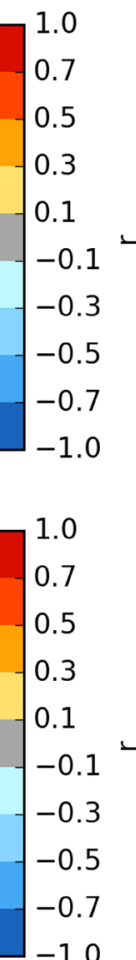

1.0
0.7
0.5
0.3
0.1
-0.1
-0.3
-0.5
-0.7
-1.0 
from all historical runs, for a given season) for all regions considered (Fig. 8). In the Arctic region, the ensemble mean decrease in frequency of occurrence is more than $36 \%$, with all ensemble members agreeing on the sign of the change (Table 3). These winter changes are largest in the AOCM region but can also be seen in the GIN and Barents Sea region as well. This signal can also be seen in the filtered vorticity distribution, which shows a similar reduction in the occurrence of the strongest vorticity events, indicating that these changes are related to the dynamical strength of the cyclones themselves, rather than due to changes in background circulation at $850 \mathrm{hPa}$ (Fig. S6).

The picture is more complex in other seasons. In JJA, within the AOCM region there is an increase in the frequency of strong events (Fig. 8f). Their occurrence significantly increases, by more than $19 \%$. Whereas in SON their frequency significantly reduces, with no significant change in MAM (Table 3).

Although the reduction in the frequency of strong events in the GINB region is strongest in winter (25\%), significant reductions are also seen in MAM and SON, but with no significant change in summer.

\section{Discussion}

The seasonal characteristics of the Arctic cyclone climatology vary dramatically by season. In winter, Arctic synoptic cyclones are largely made up of decaying cyclones from the extratropical storm tracks of the North Atlantic and north Pacific, whereas in the summer the climatology is unique to the Arctic with many cyclones originating over the northern continental regions. Similarly, in this study we find that the projected response of the Arctic cyclone climatology in CESM1 is seasonally dependent: storm dynamic intensity is significantly reduced in winter months but in summer large areas of the Arctic dynamic intensity is projected to increase.

Cyclones tend to form in regions of strong temperature gradients (Shaw et al. 2016) and we believe it is the pronounced seasonal differences in these temperature gradients that drive these changes in storminess, with high latitude temperature gradients weakening in winter and strengthening in summer. This can be seen in the ensemble mean response, however, a correlation analysis to investigate the causes of ensemble spread indicated that the ensemble variability in storminess was most highly correlated with large scale atmospheric SLP and zonal winds in a pattern resembling the AO. This may be because the atmosphere can generate significant internal variability in SLP and wind patterns, independently of changes in surface temperature (Deser et al. 2012). As a result correlations between JJA storminess indices and dSAT/dy along the Arctic coastline are not significant, unlike the CMIP3 and CMIP5 analysis of Nishii et al. (2014). This is probably because ensemble spread in the CMIP ensembles for key variables, such as dSAT/dy, is larger than in the CESM-LE. Uncertainty in the forced response of climate models tends to be a larger contribution to CMIP ensemble spread than internal variability at long timescales (Hawkins and Sutton 2009). Because the CESM-LE ensemble spread is only due to internal variability, this difference is the most likely explanation for this difference between our correlation analysis and Nishii et al.

Clearly the response of the jet stream is an important factor in the response of Arctic cyclones to climate change in CESM1 for both summer and winter. Recent studies have highlighted the importance of tropopause vorticity anomalies for the development of Arctic summer cyclones (Simmonds and Rudeva 2012; Yamazaki et al. 2015). However, relatively little is known about the mechanisms responsible for the development of Arctic synoptic scale summer cyclones and few observations exist (Aizawa and Tanaka 2016). This makes it difficult to develop a process based understanding of their likely response to changes in background climate and makes it difficult to assess the ability of climate models to realistically simulate these features. The response of the jet stream to climate change is a complex issue which we will not discuss here, however a summary of the response of the jet to climate change can be found in Barnes and Screen (2015).

The projected changes in the frequency of strong Arctic cyclones are large compared to those projected for the North Atlantic, for example. The changes in the frequency in cyclone across the North Atlantic storm track in CMIP5 models is much smaller, $-8 \pm 3 \%$ in DJF and $-6 \pm 3 \%$ in JJA according to Zappa et al. (2013a). If these results are representative of the real climate, this could have significant impacts to the frequency with which humans are exposed to extreme wind events in the Arctic.

We find a significant reduction in the mean dynamical intensity of cyclones across the Arctic basin and subpolar North Atlantic. In particular, we see a reduction in the frequency of occurrence of strong cyclones in the Arctic and GIN and Barents Sea regions. This is in contrast to the study of Vavrus (2013), who found an increase in strong cyclones in these regions. However, because this study analysed this change in different models (CMIP5 ensemble) under a different forcing protocol (historical instead of RCP8.5) and used a different procedure for counting extreme cyclones, it is difficult to understand the source of this discrepancy. The Vavrus study used a procedure for counting cyclones based on counting pressure minima. As the Arctic surface warms and lower troposphere warms in winter, there will be a reduction in the static stability and surface pressure (see Figure S3 of this paper and Jaiser et al. 2012). However, although the mean minimum sea level pressure associated with cyclone tracks in the RCP8.5 runs is lower than the 
(a) djf ARC wind 850

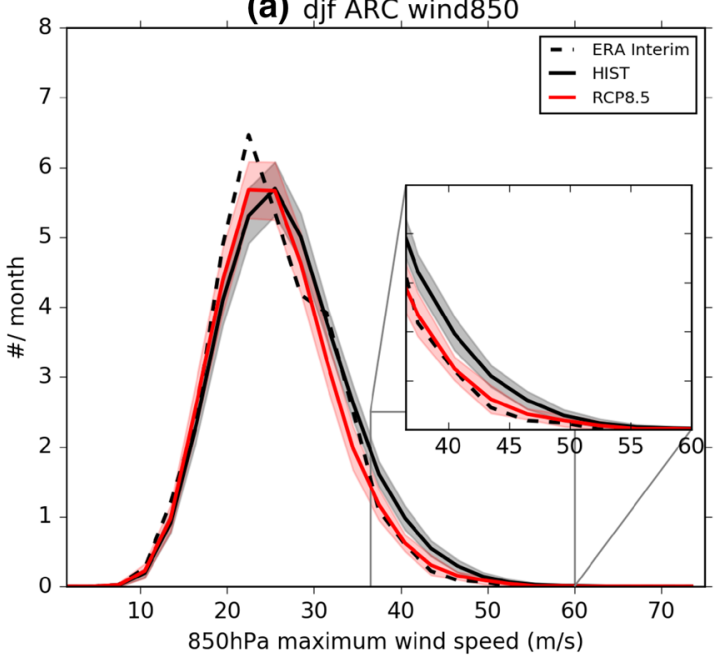

(c) djf GINB wind850

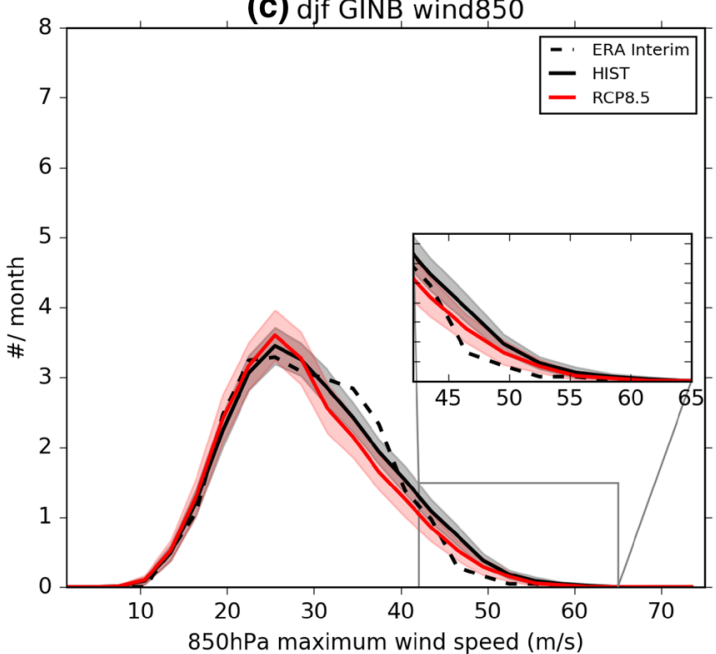

(e) djf ACM wind850

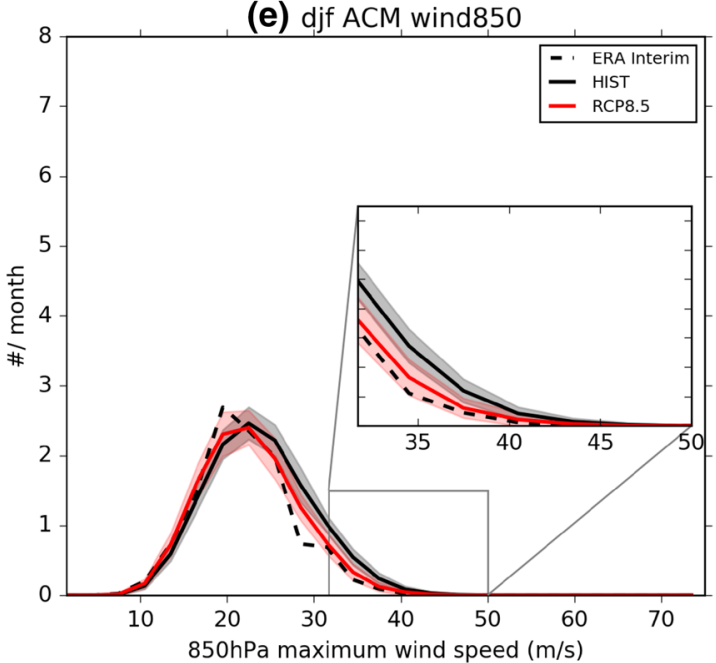

Fig. 8 Frequency distribution of maximum $850 \mathrm{hPa}$ wind speed achieved by each track within the Arctic, GIN and Barents Sea, and AOCM regions (shown in Fig. 3). The solid lines show the ensemble mean frequency distribution for the historical (1990-2005) and RCP8.5 (2071-2080) simulations. The shaded areas enclose the (b) jja ARC wind850

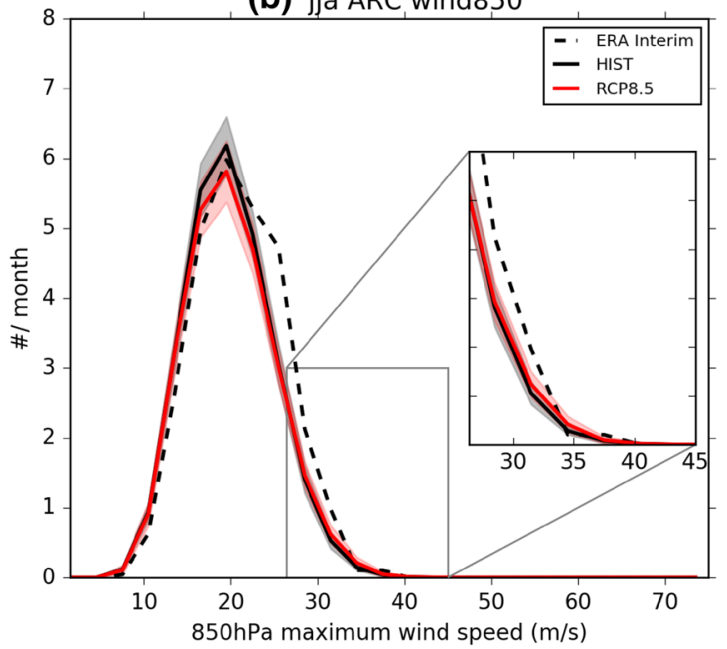

(d) jja GINB wind850

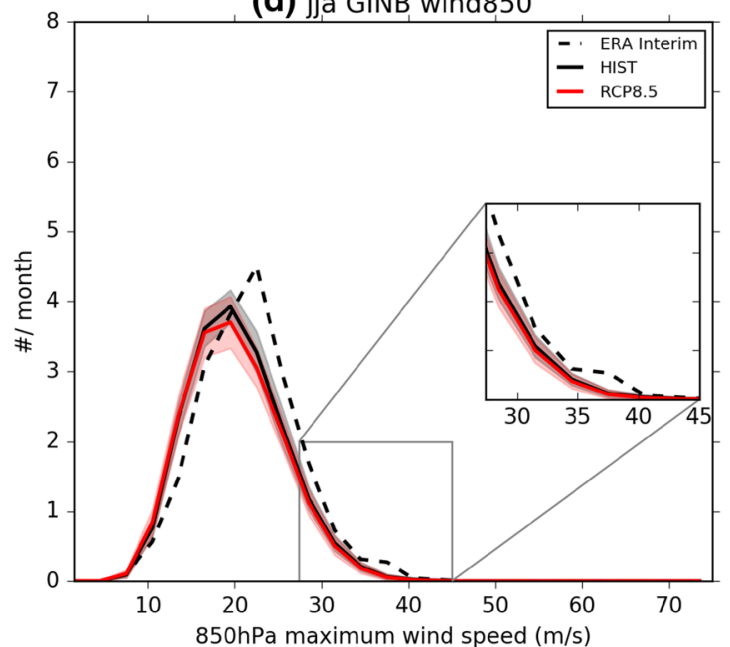

(f) jja ACM, wind850

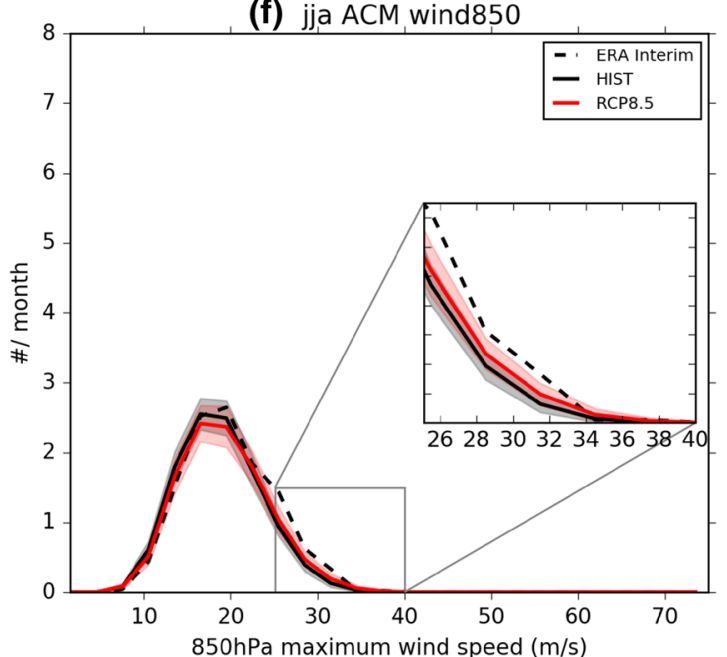

region one standard deviation away from the ensemble mean. Insets show zoomed in sections of the distribution starting at the 90th percentile of the frequency distribution, based on the historical simulations. The dashed line shows the equivalent distribution for the ERAInterim (1990-2005) 
Table 3 Changes in the frequency of 90th percentile events. The ensemble mean change in the frequency strong events between the historical simulation (1990-2005) and RCP8.5 simulations (20712080), based on the 90th percentile of maximum wind speed of cyclones within the Arctic, AOCM and GIN and Barents Sea region.
Changes are expressed as a percentage of the historical values. The percentage of ensemble members that agree on the sign of the change is stated as a measure of significance. Changes where more than $80 \%$ of ensemble members agree on the sign of the change are highlighted in bold

\begin{tabular}{|c|c|c|c|c|}
\hline & DJF & MAM & JJA & SON \\
\hline \multicolumn{5}{|l|}{ Arctic } \\
\hline Change in frequency and $\%$ agreement & $-\mathbf{3 6 . 1}(100)$ & $-12.7(70)$ & $9.1(70)$ & $-10.7(72)$ \\
\hline \multicolumn{5}{|l|}{ AOCM } \\
\hline Change in frequency and $\%$ agreement & $\mathbf{- 3 7 . 1}(97)$ & $2.3(57)$ & $19.7(80)$ & $-20.5(85)$ \\
\hline \multicolumn{5}{|l|}{ GIN and Barents } \\
\hline Change in frequency and $\%$ agreement & $\mathbf{- 2 5 . 0}(92)$ & $-\mathbf{1 8 . 1}(85)$ & $-5.7(65)$ & $-\mathbf{1 3 . 4}(82)$ \\
\hline
\end{tabular}

HIST runs, this does not seem to lead to enhanced maximum cyclone vorticity, or maximum wind speed in our analysis (see Fig. 9, S6). One possible explanation is that the radius of cyclones may also be changing so that pressure gradients in cyclones are similar.

The choice of variable and details of the method used to detect and track cyclones can significantly affect the outcome of climate change studies, particularly for investigating extremes. For example, Chang (2014) found that defining cyclones as perturbations to the background flow, rather than using a threshold led to the desirable property of higher correlations with changes in frequency of high wind events and mean available potential energy.

This complexity can be seen by considering distributions of a number of cyclone intensity measures for our AOCM region. In DJF, this region experiences the most dramatic decrease in cyclone intensity within the Arctic, as measured by $850 \mathrm{hPa}$ wind speed, but also largest changes in seasonal mean MSLP (Fig. 4). The distributions of maximum $850 \mathrm{hPa}$ wind speed, $850 \mathrm{hPa}$ smoothed vorticity and minimum MSLP suggest different conclusions (Fig. 9). The reduced values of wind speed and vorticity measures indicate a reduction in dynamical intensity, but the deepening of MSLP indicates the opposite. This suggests that multiple intensity measures should be considered when investigating changes in cyclone extremes, in order to separate changes in the cyclones themselves from changes in their environment.

\section{Conclusions}

We have examined the seasonal response of Arctic cyclones to climate change between 1990-2005 and 2071-2080 under an RCP8.5 emissions scenario in the CESM1 large ensemble. Although this model performs relatively well in reproducing the basic features of the Arctic cyclone climatology, it suffers from biases common to other coupled climate models, such as low track density during Arctic summer.
As well as examining the response of the ensemble mean we also utilised intra-ensemble variability in the change simulated between these two periods to explore the relationship between cyclone statistics and changes in the background state, namely changes in $850 \mathrm{hPa}$ zonal wind and the meridional temperature gradients. This enabled us to test hypotheses relating changes in cyclone statistics to the background climate in an analogous way to that which has been done in a multi-model ensemble (e.g. Nishii et al. 2014) for the first time.

The following points summarise our conclusions:

- We find significant reduction in both the number of cyclones in the Arctic and their maximum wind speed within the Arctic during winter months. We also find a significant reduction of over $36 \%$ in the frequency with which strong (90th percentile) cyclones occur.

- We hypothesise that the reduction in winter storminess is caused by a reduction in the equator-pole temperature gradient, resulting from amplified Arctic warming.

- In contrast, a strengthening of JJA cyclone intensity within the AOCM region is associated with increased meridional surface temperature gradients along the Arctic coastline and a strengthening of zonal winds in the same region. This is caused by enhanced warming of high latitude continents compared to the Arctic Ocean.

- The frequency with which strong cyclones occur within the AOCM during JJA increases by $19.7 \%$.

The differences in the seasonality of the response can therefore be tied to thermodynamic properties of the surface climate, which are understood with high confidence. However, relating changes in the average properties of Arctic cyclones to changes in their background state is difficult, due to the number of competing factors involved (e.g. Shaw et al. 2016).

Firstly, changes in local baroclinicity may not lead to the expected response in cyclones because individual 
(a) $\operatorname{djf}$ ACM wind850

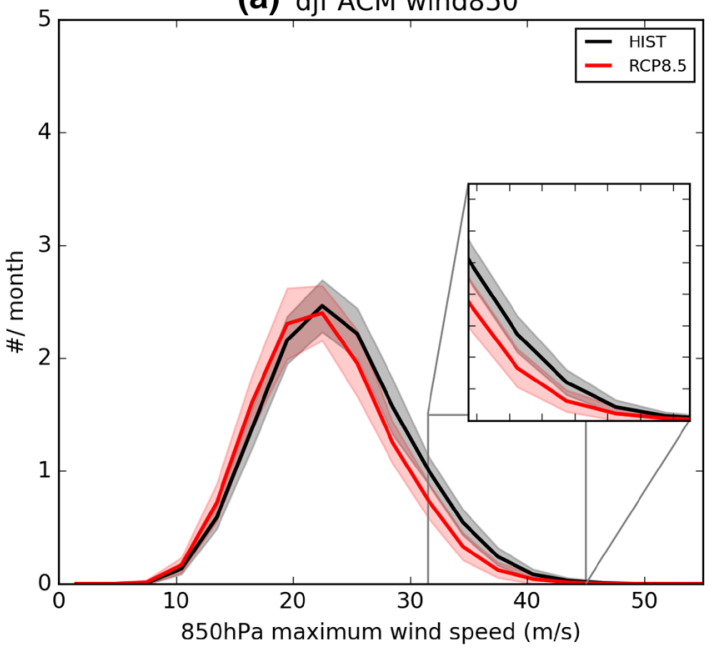

(c) djf ACM vor850T42

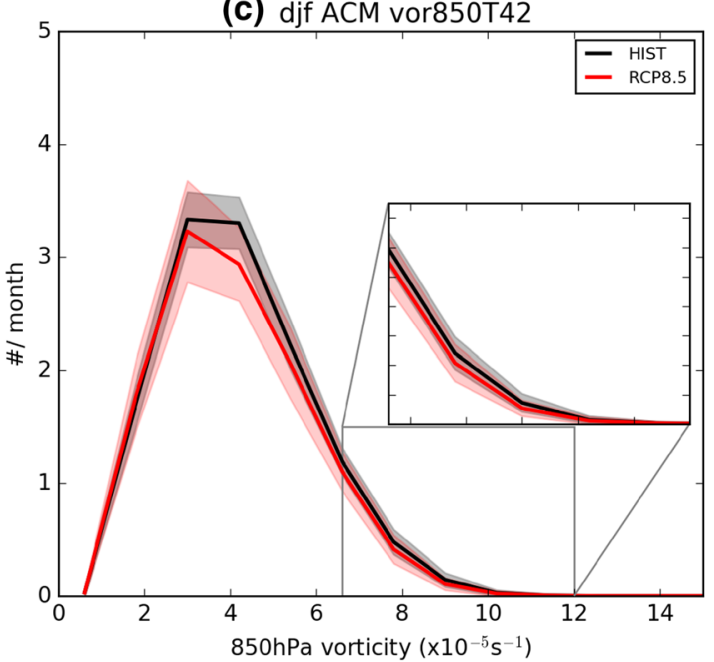

(e) $\operatorname{djf}$ ACM mslp

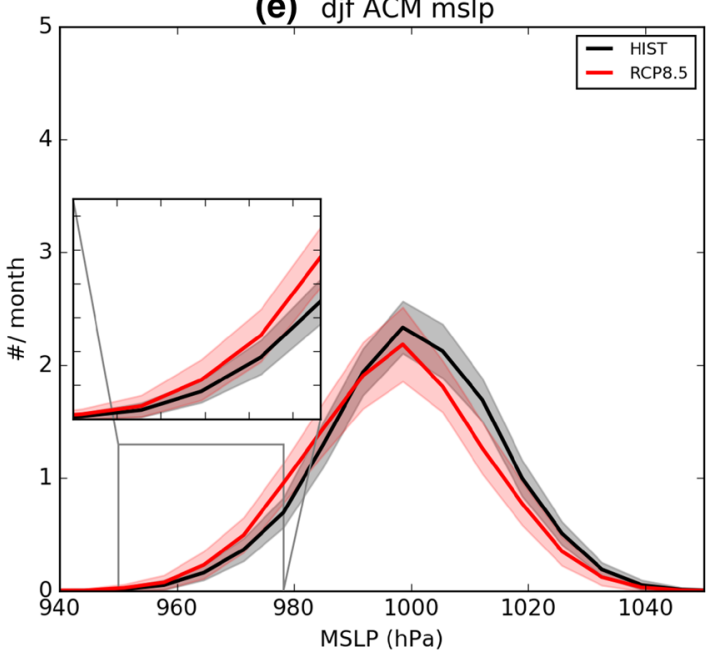

Fig. 9 Frequency distribution of maximum $850 \mathrm{hPa}$ wind speed (a, b), maximum smoothed vorticity $(\mathbf{c}, \mathbf{d})$ and minimum $\operatorname{MSLP}(\mathbf{e}, \mathbf{f})$ achieved by each track within the AOCM region (shown in Fig. 3). The solid lines show the ensemble mean frequency distribution for the historical (1990-2005) and RCP8.5 (2071-2080) simulations.

(b) jja ACM wind850

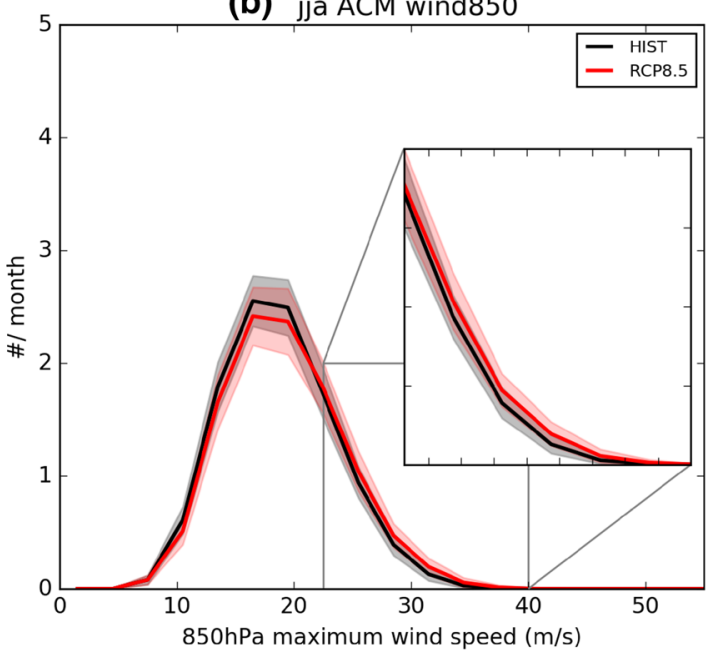

(d) jja ACM vor850T42

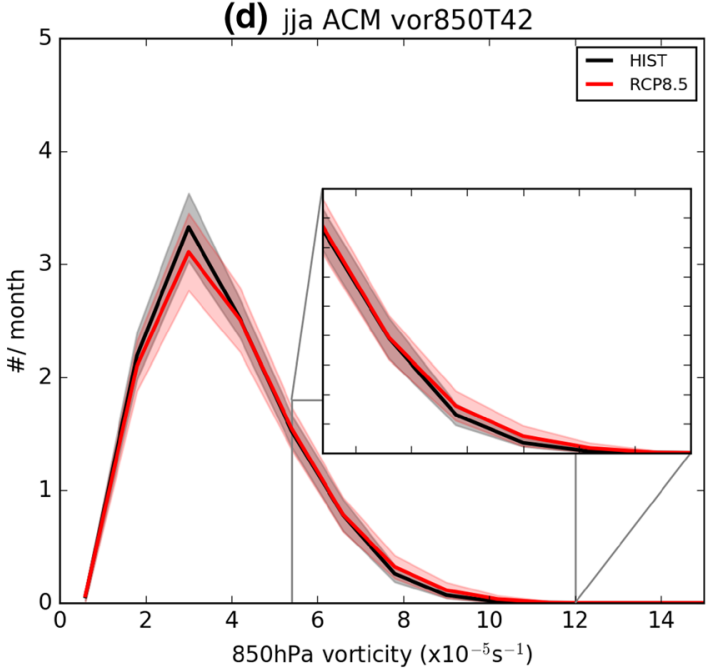

(f) jja ACM mslp

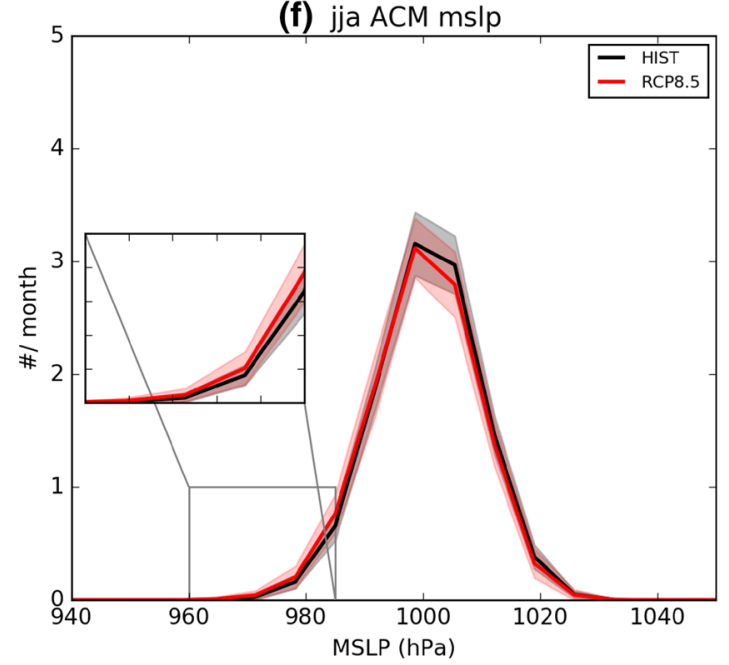

The shaded areas enclose the region one standard deviation away from the ensemble mean. Insets show zoomed in sections of the distribution starting at the 90th percentile of the frequency distribution, based on the historical simulations 
depressions may travel large distances and may be affected by changes in climate along their whole trajectory. Secondly, changes in background climate often have an opposing effect on storminess, for example in DJF static stability is reduced which in isolation would be expected to lead to enhanced synoptic activity (e.g. Hoskins and Valdes 1990), whereas the reduction in zonal wind speed and reduced dSAT/dy act in the opposite direction. Therefore, the balance of these factors is crucial for accurately predicting the response of Arctic cyclones to climate change.

Trends of different sign in cyclone intensity in different seasons is an interesting feature of the climate response in this region. We have suggested mechanisms for this associated with changes in mean zonal wind patterns and changes in the baroclinic zones in the high latitudes, but it will be necessary to conduct targeted experiments to look at each of these mechanisms to confirm these hypotheses, as there are many competing factors in the RCP8.5 scenario.

Acknowledgements The authors would like to thank Giuseppe Zappa, University of Reading, for advice regarding processing of the large ensemble and Steve Vavrus and John Mioduszewski, University of Wisconsin, for interesting discussions about cyclone tracking in the Arctic. Jonathan Day was supported by an AXA Post-Doctoral Research Fellowship and the NCAR visitor fund.

Open Access This article is distributed under the terms of the Creative Commons Attribution 4.0 International License (http://creativeco mmons.org/licenses/by/4.0/), which permits unrestricted use, distribution, and reproduction in any medium, provided you give appropriate credit to the original author(s) and the source, provide a link to the Creative Commons license, and indicate if changes were made.

\section{References}

Aizawa T, Tanaka HL (2016) Axisymmetric structure of the long lasting summer Arctic cyclones. Polar Sci 10:192-198. https://doi. org/10.1016/j.polar.2016.02.002

Akperov M, Mokhov I, Rinke A et al (2014) Cyclones and their possible changes in the Arctic by the end of the twenty first century from regional climate model simulations. Theor Appl Climatol. https://doi.org/10.1007/s00704-014-1272-2

Barnes EA, Screen JA (2015) The impact of Arctic warming on the midlatitude jet-stream: can it? Has it? Will it? Wiley Interdiscip Rev Clim Change 6:277-286. https://doi.org/10.1002/wcc.337

Bengtsson L, Hodges KI, Roeckner E (2006) Storm tracks and climate change. J Clim 19:3518-3543

Branstator G, Teng H (2010) Two limits of initial-value decadal predictability in a CGCM. J Clim 23:6292-6311. https://doi. org/10.1175/2010JCLI3678.1

Chang EKM (2014) Impacts of background field removal on CMIP5 projected changes in Pacific winter cyclone activity: CMIP5 projection of Pacific cyclones. J Geophys Res Atmos 119:46264639. https://doi.org/10.1002/2013JD020746

Collins M, Botzet M, Carril AF et al (2006) Interannual to decadal climate predictability in the North Atlantic: a multimodelensemble study. J Clim 19:1195-1203
Crawford AD, Serreze MC (2016) Does the summer Arctic frontal zone influence Arctic Ocean cyclone activity? J Clim 29:49774993. https://doi.org/10.1175/JCLI-D-15-0755.1

Day JJ, Hargreaves JC, Annan JD, Abe-Ouchi A (2012) Sources of multi-decadal variability in Arctic sea ice extent. Environ Res Lett 7:034011. https://doi.org/10.1088/1748-9326/7/3/034011

Dee DP, Uppala SM, Simmons AJ et al (2011) The ERA-Interim reanalysis: configuration and performance of the data assimilation system. Q J R Meteorol Soc 137:553-597. https://doi org/10.1002/qj.828

Deser C, Phillips A, Bourdette V, Teng H (2012) Uncertainty in climate change projections: the role of internal variability. Clim Dyn 38:527-546. https://doi.org/10.1007/s00382-010-0977-x

Emmerson C, Lahn G (2012) Arctic opening: opportunity and risk in the high north. Lloyds, Chattham House, London

Francis JA, Vavrus SJ (2012) Evidence linking Arctic amplification to extreme weather in mid-latitudes. Geophys Res Lett. https://doi. org/10.1029/2012GL051000

Gervais M, Atallah E, Gyakum JR, Tremblay LB (2016) Arctic air masses in a warming world. J Clim 29:2359-2373. https://doi. org/10.1175/JCLI-D-15-0499.1

Hall A, Qu X (2006) Using the current seasonal cycle to constrain snow albedo feedback in future climate change. Geophys Res Lett 33:L03502. https://doi.org/10.1029/2005GL025127

Harvey BJ, Shaffrey LC, Woollings TJ (2014) Equator-to-pole temperature differences and the extra-tropical storm track responses of the CMIP5 climate models. Clim Dyn 43:1171-1182. https:// doi.org/10.1007/s00382-013-1883-9

Hawkins E, Sutton R (2009) The potential to narrow uncertainty in regional climate predictions. BAMS 90:1095-1107. https://doi. org/10.1175/2009BAMS2607.1

Hawkins E, Tietsche S, Day JJ et al (2016) Aspects of designing and evaluating seasonal-to-interannual Arctic sea-ice prediction systems. Q J R Meteorol Soc 142:672-683. https://doi.org/10.1002/ qj. 2643

Hodges KI (1994) A general method for tracking analysis and its application to meteorological data. Mon Weather Rev 122:2573-2586. https://doi.org/10.1175/1520-0493(1994)122<2573:AGMFT $\mathrm{A}>2.0 . \mathrm{CO} ; 2$

Hodges KI (1996) Spherical nonparametric estimators applied to the UGAMP model integration for AMIP. Mon Weather Rev 124:2914-2932. https://doi.org/10.1175/15200493(1996)124<2914:SNEATT>2.0.CO;2

Hodges KI (1999) Adaptive constraints for feature tracking. Mon Weather Rev 127:1362-1373. https://doi.org/10.1175/15200493(1999)127<1362:ACFFT > 2.0.CO;2

Hodges KI, Lee RW, Bengtsson L (2011) A comparison of extratropical cyclones in recent reanalyses ERA-Interim, NASA MERRA, NCEP CFSR, and JRA-25. J Clim 24:4888-4906. https://doi. org/10.1175/2011JCLI4097.1

Hodson DLR, Keeley SPE, West A et al (2012) Identifying uncertainties in Arctic climate change projections. Clim Dyn. https://doi. org/10.1007/s00382-012-1512-z

Holland MM, Bitz CM (2003) Polar amplification of climate change in coupled models. Clim Dyn 21:221-232.

Hoskins BJ, Hodges KI (2002) New perspectives on the Northern Hemisphere winter storm tracks. J Atmos Sci 59:1041-1061

Hoskins BJ, Valdes PJ (1990) On the existence of storm-tracks. J Atmos Sci 47:1854-1864. https://doi.org/10.1175/15200469(1990)047<1854:OTEOST>2.0.CO;2

Hurrell JW, Holland MM, Gent PR et al (2013) The community earth system model: a framework for collaborative research. Bull Am Meteorol Soc 94:1339-1360. https://doi.org/10.1175/BAMSD-12-00121.1 
Jahn A, Kay JE, Holland MM, Hall DM (2016) How predictable is the timing of a summer ice-free Arctic? Geophys Res Lett. https://doi. org/10.1002/2016GL070067

Jaiser R, Dethloff K, Handorf D et al (2012) Impact of sea ice cover changes on the Northern Hemisphere atmospheric winter circulation. Tellus A. https://doi.org/10.3402/tellusa.v64i0.11595

Jung T, Gordon ND, Bauer P et al (2016) Advancing polar prediction capabilities on daily to seasonal time scales. Bull Am Meteorol Soc 97:1631-1647. https://doi.org/10.1175/BAMS-D-14-00246.1

Kay JE, Deser C, Phillips A et al (2015) The community earth system model (CESM) large ensemble project: a community resource for studying climate change in the presence of internal climate variability. Bull Am Meteorol Soc 96:1333-1349. https://doi. org/10.1175/BAMS-D-13-00255.1

Kistler R, Kalnay E, Collins W et al (2001) The NCEP-NCAR 50-year reanalysis: monthly means CD-ROM and documentation. Bull Am Meteorol Soc 82:247-267

Klein T, Heinemann G (2002) Interaction of katabatic winds and mesocyclones near the eastern coast of Greenland. Meteorol Appl 9:407-422. https://doi.org/10.1017/S1350482702004036

Knudsen EM, Orsolini YJ, Furevik T, Hodges KI (2015) Observed anomalous atmospheric patterns in summers of unusual Arctic sea ice melt. J Geophys Res Atmos 120:2014JD022608. https:// doi.org/10.1002/2014JD022608

Lauritzen PH, Mirin AA, Truesdale J et al (2012) Implementation of new diffusion/filtering operators in the CAM-FV dynamical core. Int J High Perform Comput Appl 26:63-73. https://doi. org/10.1177/1094342011410088

Lee RW (2014) Storm track biases and changes in a warming climate from an extratropical cyclone perspective using CMIP5. PhD Thesis, University of Reading

Lin S-J (2004) A "Vertically Lagrangian" finite-volume dynamical core for global models. Mon Weather Rev 132:2293-2307. https://doi. org/10.1175/1520-0493(2004)132<2293:AVLFDC>2.0.CO;2

Manabe S, Stouffer RJ (1980) Sensitivity of a global climate model to an increase of $\mathrm{CO}_{2}$ concentration in the atmosphere. J Geophys Res Oceans 85:5529-5554. https://doi.org/10.1029/JC085iC10p 05529

Neale RB, Chen C-C, Gettelman A et al (2010) Description of the NCAR community atmosphere model (CAM 5.0). NCAR Technical Note, National Center of Atmospheric Research

Neale RB, Richter J, Park S et al (2013) The mean climate of the community atmosphere model (CAM4) in forced SST and fully coupled experiments. J Clim 26:5150-5168. https://doi.org/10.1175/ JCLI-D-12-00236.1

Nishii K, Nakamura H, Orsolini YJ (2014) Arctic summer storm track in CMIP3/5 climate models. Clim Dyn. https://doi.org/10.1007/ s00382-014-2229-y

Orsolini YJ, Sorteberg A (2009) Projected changes in Eurasian and Arctic summer cyclones under global warming in the Bergen climate model. Atmos Ocean Sci Lett 2:62-67. https://doi.org/10.1 111/j.1600-0870.2008.00305.x

Reed RJ, Kunkel BA (1960) The Arctic circulation in summer. J Meteorol 17:489-506. https://doi.org/10.1175/15200469(1960)017<0489:TACIS > 2.0.CO;2

Rigor IG, Colony RL, Martin S (2000) Variations in surface air temperature observations in the Arctic, 1979-1997. J Clim 13:896-914

Sardeshmukh PD, Hoskins BI (1984) Spatial smoothing on the sphere. Mon Weather Rev 112:2524-2529

Screen JA, Simmonds I (2010) The central role of diminishing sea ice in recent Arctic temperature amplification. Nature 464:1334-1337

Screen JA, Simmonds I, Keay K (2011) Dramatic interannual changes of perennial Arctic sea ice linked to abnormal summer storm activity. J Geophys Res. https://doi.org/10.1029/2011J D015847
Sepp M, Jaagus J (2011) Changes in the activity and tracks of Arctic cyclones. Clim Change 105:577-595. https://doi.org/10.1007/ s10584-010-9893-7

Serreze MC (1995) Climatological aspects of cyclone development and decay in the Arctic. Atmos Ocean 33:1-23. https://doi. org/10.1080/07055900.1995.9649522

Serreze MC, Barrett AP (2008) The summer cyclone maximum over the Central Arctic Ocean. J Clim 21:1048-1065. https://doi. org/10.1175/2007JCLI1810.1

Serreze MC, Barrett AP, Stroeve JC, et al (2009) The emergence of surface-based Arctic amplification. Cryosphere 3:11-19.

Shaw TA, Baldwin M, Barnes EA, et al (2016) Storm track processes and the opposing influences of climate change. Nat Geosci 9:656-664. https://doi.org/10.1038/ngeo2783

Shepherd TG (2016) Effects of a warming Arctic. Science 353:989_ 990. https://doi.org/10.1126/science.aag2349

Simmonds I, Keay K (2009) Extraordinary September Arctic sea ice reductions and their relationships with storm behavior over 1979-2008. Geophys Res Lett. https://doi.org/10.1029/2009G L039810

Simmonds I, Rudeva I (2012) The great Arctic cyclone of August 2012. Geophys Res Lett 39. https://doi.org/10.1029/2012G L054259

Simmonds I, Rudeva I (2014) A comparison of tracking methods for extreme cyclones in the Arctic basin. Tellus A. https://doi. org/10.3402/tellusa.v66.25252

Simmonds I, Burke C, Keay K (2008) Arctic climate change as manifest in cyclone behavior. J Clim 21:5777-5796. https:// doi.org/10.1175/2008JCLI2366.1

Sinclair MR (1997) Objective identification of cyclones and their circulation intensity, and climatology. Weather Forecast 12:595-612. https://doi.org/10.1175/15200434(1997)012<0595:OIOCAT >2.0.CO;2

Sorteberg A, Walsh JE (2008) Seasonal cyclone variability at $70^{\circ} \mathrm{N}$ and its impact on moisture transport into the Arctic. Tellus A 60:570-586. https://doi.org/10.1111/j.1600-0870.2008.00314.x

Stroeve JC, Serreze MC, Holland MM, et al (2011) The Arctic's rapidly shrinking sea ice cover: a research synthesis. Clim Change. https://doi.org/10.1007/s10584-011-0101-1

Suarez MJ, Takacs LL (1995) Technical report series on global modeling and data assimilation. Volume 5: documentation of the AIRES/GEOS dynamical core, version 2

Swart NC, Fyfe JC, Hawkins E, et al (2015) Influence of internal variability on Arctic sea-ice trends. Nat Clim Change 5:86-89

Tanaka HL, Yamagami A, Takahashi S (2012) The structure and behavior of the arctic cyclone in summer analyzed by the JRA25/JCDAS data. Polar Sci 6:55-69. https://doi.org/10.1016/j. polar.2012.03.001

Taylor KE, Stouffer RJ, Meehl GA (2012) An overview of CMIP5 and the experiment design. Bull Am Meteorol Soc 93:485-498. https://doi.org/10.1175/BAMS-D-11-00094.1

Tilinina N, Gulev SK, Bromwich DH (2014) New view of Arctic cyclone activity from the Arctic system reanalysis. Geophys Res Lett 41:2013GL058924. https://doi.org/10.1002/2013GL058924

Uppala SM, Kallberg PW, Simmons AJ et al (2005) The ERA-40 re-analysis. Q J R Meteorol Soc 131:2961-3012

Vavrus SJ (2013) Extreme Arctic cyclones in CMIP5 historical simulations. Geophys Res Lett 40:6208-6212. https://doi. org/10.1002/2013GL058161

Villarini G, Vecchi GA (2012) Twenty-first-century projections of North Atlantic tropical storms from CMIP5 models. Nat Clim Change 2:604-607. https://doi.org/10.1038/nclimate1530

Yamazaki A, Inoue J, Dethloff K et al (2015) Impact of radiosonde observations on forecasting summertime Arctic cyclone formation: Arctic radiosondes for cyclone forecast. J Geophys Res Atmos 120:3249-3273. https://doi.org/10.1002/2014JD022925 
Zappa G, Shaffrey LC, Hodges KI et al (2013a) A multimodel assessment of future projections of North Atlantic and European extratropical cyclones in the CMIP5 climate models. J Clim 26:5846-5862

Zappa G, Shaffrey LC, Hodges KI (2013b) The ability of CMIP5 models to simulate North Atlantic extratropical cyclones. J Clim 26:5379-5396. https://doi.org/10.1175/JCLI-D-12-00501.1
Zhang X, Walsh JE, Zhang J et al (2004) Climatology and interannual variability of arctic cyclone activity: 1948-2002. J Clim 17:2300-2317

Zhang J, Lindsay R, Schweiger A, Steele M (2013) The impact of an intense summer cyclone on 2012 Arctic sea ice retreat. Geophys Res Lett 40:720-726. https://doi.org/10.1002/grl.50190 